\title{
De las licencias urbanísticas a las declaraciones responsables ${ }^{1}$
}

\section{From urban licenses to responsible statements}

\author{
Manuel Rebollo Puig \\ Universidad de Córdoba (España) \\ ORCID: https://orcid.org/0000-0002-4803-7967 \\ manuel.rebollo.puig@uco.es
}

\section{NOTA BIOGRÁFICA}

Catedrático de Derecho Administrativo en la Universidad de Córdoba desde 1994. Líneas de investigación: Fuentes del Derecho, organización, actividad, medios y control de la Administración pública, Derecho Administrativo sancionador.

\section{RESUMEN}

Se analiza qué licencias urbanísticas pueden o deben sustituirse por comunicaciones o declaraciones responsables, en qué casos lo permite o hasta impone la legislación estatal y en qué medida lo han hecho ya las leyes autonómicas. También qué alcance deben tener estas cargas alternativas de modo que entrañen una auténtica simplificación y no se arruinen las ventajas de la opción por estos controles más livianos.

\section{PALABRAS CLAVE}

Autorizaciones; comunicaciones; declaraciones responsables; urbanismo; licencias urbanísticas.

\section{ABSTRACT}

This paper analyses which urban licenses can or must be replaced by communications or responsible statements, in which cases it is allowed or even imposed by the state legislation and to what extent the regional laws have already done it. Also, it is analysed what scope these alternative charges should have so that they involve a real simplification and do not ruin the advantages of the option for these lighter controls.

\section{KEYWORDS}

Authorisations; communications; responsible statements; urbanism; urban licenses.

\section{SUMARIO}

1. PLANTEAMIENTO Y OBJETIVOS. 2. CONDICIONANTES DE LA LEGISLACIÓN ESTATAL EN CUANTO A LA SUPRESIÓN DE LICENCIAS URBANÍSTICAS. 2.1. LICENCIAS URBANÍSTICAS EN LEGISLACIÓN ESTATAL DE SUELO. 2.1.1. Casos en que impone licencias. 2.2. Las licencias urbanísticas en la Ley estatal 12/2012. 2.2.1. Actividades o establecimientos a los que afecta la Ley 12/2012. 2.2.2. Licencias urbanísticas suprimidas por esta Ley: las de ciertas obras y las de utilización 2.2.3. Posibilidad autonómica de eximir otras actuaciones de licencia y hasta de declaración responsable o comunicación. 3. LA SUPRESIÓN DE LICENCIAS URBANÍSTICAS EN LA LEGISLACIÓN AUTONÓMICA. 4. PROPUESTA SOBRE

1 Trabajo realizado en el marco del Proyecto de Investigación del Ministerio de Economía y Competitividad DER2015-67695-C2-1-P (MINE-CO/FEDER, UE). Grupo de investigación de la Junta de Andalucía SEJ-196. 


\begin{abstract}
EL ALCANCE DE LA SUPRESIÓN DE LICENCIAS URBANÍSTICAS. 4.1. DEBE SER LA LEY LA QUE DECIDA LAS ACTUACIONES SUJETAS A LICENCIA, A COMUNICACIÓN O A DECLARACIÓN RESPONSABLE. 4.2. PROPUESTA DE SUPRESIÓN DE CONCRETAS LICENCIAS URBANÍSTICAS. 4.2.1. Obras. 4.2.2. Utilización, ocupación y cambio de uso. 4.2.3. Otros supuestos. 4.3. EL COMPLEMENTARIO REVERSO DE LA PROPUESTA: TODAS LAS LICENCIAS SUBSISTENTES DEBEN TENER SILENCIO NEGATIVO. 4.4. ACTUACIONES EXONERADAS DE TODA CARGA FORMAL PREVIA. 5. ¿SUSTITUCIÓN POR COMUNICACIÓN O POR DECLARACIÓN RESPONSABLE?. 5.1. OPCIÓN POR LA DECLARACIÓN RESPONSABLE. 5.2. CONTENIDO. 5.3. DOCUMENTACIÓN ADJUNTA. 5.4. EN ESPECIAL, MANIFESTACIONES Y DOCUMENTOS SOBRE CUMPLIMIENTO DE DEBERES TRIBUTARIOS. 6. MOMENTO EN QUE DEBEN PRESENTARSE LAS DECLARACIONES RESPONSABLES.
\end{abstract}

\title{
1. PLANTEAMIENTO Y OBJETIVOS
}

La legislación urbanística española (la estatal y luego más aún la autonómica) consagró ampliamente la necesidad de licencias ${ }^{2}$. Sobre esa situación incidió e incide la normativa general tendente a la supresión de autorizaciones y a su sustitución por comunicaciones o declaraciones responsables que tuvo su pistoletazo de salida con la celebérrima Directiva de Servicios y que encontró en España no sólo una transposición radical $^{3}$, que comenzó con la apodada "Ley Paraguas» ${ }^{4}$, sino complementos, ya al margen de esa Directiva. Sobre todo, en la Ley 20/2013 de Garantía de la Unidad de Mercado (en lo sucesivo, LGUM) ${ }^{5}$. De esta legislación se deducen los siguientes elementos fundamentales:

Fin.- Sólo cabe someter actuaciones privadas a la obtención de autorizaciones para la protección de ciertos intereses generales, no de cualquiera de ellos. En principio eran todas las denominadas razones imperiosas de interés general; hoy sólo algunas de esas razones, o sea, sólo algunos intereses generales.

Proporcionalidad.- Incluso si se trata de proteger esos selectos intereses generales, la sujeción a autorización sólo procede cuando sea un medio proporcionado, esto es, el menos restrictivo de entre los aptos para conseguir el fin. Ello se traduce en que sólo es lícita cuando su objetivo no pueda lograrse con comunicaciones o declaraciones responsables unidas a la vigilancia administrativa posterior, esto es, si este otro control más liviano sería insuficiente, sobre todo si llegaría «demasiado tarde para ser realmente eficaz».

Exigencia de ley.- La regla general es la no sujeción a autorización; la excepción es la exigencia de ésta. Y las excepciones deben establecerse en norma con rango de ley (si acaso también en un reglamento con expresa e inequívoca habilitación legal) ${ }^{6}$. Dicho de otra forma, es el legislador quien debe hacer el juicio de proporcionalidad y en su virtud decidir someter una actuación privada a la necesidad de autorización previa o exonerarla de ella.

Las licencias urbanísticas superan el primer requisito: sin duda por su fin pueden subsistir ${ }^{7}$. Pero suscitan una cuestión de proporcionalidad: su pervivencia o supresión depende de un juicio de proporcionalidad.

2 A ello se sumó una jurisprudencia que sistemáticamente optó por una interpretación extensiva de la necesidad de licencia urbanística para prácticamente todo uso del suelo que excediera del uso natural agrario. Ofrece un buen panorama F. IGLESIAS GONZÁLEZ, Licencias urbanísticas, Francis Lefebvre, Madrid, 2000, págs. 15 a 42 y 69-70.

3 Vid. R. RIVERO ORTEGA, “La trasposición de la Directiva de Servicios en España”, en R. RIVERO ORTEGA (dir.), Mercado europeo y reformas administrativas. La transposición de la Directiva de Servicios en España, Civitas, Cizur Menor, 2009 , págs. 59 a 88.

4 Es la Ley 17/2009, de 23 de noviembre, sobre libre acceso a las actividades de servicio y su ejercicio, que aquí citaremos por su apodo de «Ley Paraguas».

5 Sobre lo que esta legislación comporta para el sometimiento de actividades privadas a controles administrativos previos vid. M. REBOLLO PUIG, "El principio de necesidad y proporcionalidad de los límites a las actividades económicas", en J. GUILLÉN CARAMÉS, M. CUERDO MIR (dirs.) y L. RAMS RAMOS (coord.), Estudios sobre la Ley de Garantía de la Unidad de Mercado, Civitas, Cizur Menor, 2017, págs. 127 a 137. También M. REBOLLO PUIG, "El Estado autonómico tras la Ley de Garantía de la Unidad de Mercado y sus principios de necesidad y eficacia nacional", Revista Andaluza de Administración Pública, núm. 91 (2015), sobre todo, págs. 108 a 112; y en M. LÓPEZ BENÍTEZ, J. A. FUENTETAJA PASTOR y S. RODRÍGUEZ-CAMPOS GONZÁLEZ, Las reformas administrativas de la crisis, Civitas, 2017, págs. 94 a 99. La LGUM ha sido parcialmente anulada (SSTC 79, 110, 111 y 119/2017). Pero las anulaciones no afectan a su plasmación radical del principio de proporcionalidad respecto a sujeción a autorizaciones, que es lo que aquí interesa.

6 En la legislación local, que nos interesa aquí particularmente, esto queda reflejado en el art. 84 bis LRBRL (tras su incorporación por Ley 2/2011 de Economía Sostenible y su reforma por Ley 27/2013, de Racionalización y Sostenibilidad de la Administración Local). Su apartado 1 proclama que «con carácter general, el ejercicio de actividades no se someterá a la obtención de licencia...». Su apartado 2 dice que «las instalaciones o infraestructuras físicas para el ejercicio de actividades económicas sólo se someterán a un régimen de autorización cuando lo establezca una Ley...». Refuerza la exigencia de ley el art. 17.1 LGUM y en Andalucía el art. 3.1 de su Ley 3/2014 de medidas normativas para reducir las trabas administrativas.

7 En realidad, las licencias urbanísticas ni siquiera eran en principio objeto directo de esa legislación que se centraba inicialmente en las autorizaciones de actividades de servicio y después más ampliamente de actividades económicas. Así, la propia Directiva de Servicios aclara en su considerando 9: «La presente Directiva (...) no se aplica a requisitos tales como (...) normas relativas a la orde- 
Juicio del legislador que, desde luego, no se puede hacer en bloque de todas ellas, que son variopintas y de muy diverso calado, sino de cada uno de sus géneros. También su eventual sustitución por comunicaciones o declaraciones responsables, así como el contenido y régimen de éstas, está sometido al principio de proporcionalidad.

Este nuevo marco ya ha dado algunos frutos que, en efecto, han supuesto cierta disminución de la exigencia de licencias urbanísticas. Se analizarán aquí. Pero también interesa apuntar -y también será objeto del estudio- qué otros pasos pueden darse en la misma dirección para formar un sistema más coherente.

\section{CONDICIONANTES DE LA LEGISLACIÓN ESTATAL EN CUANTO A LA SUPRESIÓN DE LICENCIAS URBANÍSTICAS}

Siendo el urbanismo competencia de las Comunidades Autónomas, son éstas (sus respectivas asambleas legislativas) las que deben decidir qué actuaciones requieren licencias municipales, cuáles necesitan algo más (por ejemplo, aprobaciones de la Administración autonómica si afectan al suelo no urbanizable), qué otras quedarán sometidas a comunicación o a declaración responsable y cuáles, incluso, quedarán exoneradas de cualquiera de esas cargas formales. Y, además, es a ellas a las que compete establecer todo el régimen de las licencias y de las comunicaciones y declaraciones responsables que prevean. Pero el Estado conserva competencias (especialmente las del art. 149.1.13. ${ }^{a}$ y $18 .^{a} \mathrm{CE}$ ) que le permiten entrar limitadamente en este aspecto: no sólo establecer el marco general de supresión de autorizaciones en cualquier sector sino concretamente respecto a las licencias urbanísticas. Y así lo ha hecho. Está plasmado en el Texto Refundido de la Ley de Suelo y Rehabilitación Urbana (Real Decreto Legislativo 7/2015, de 30 de octubre; en adelante LS/15) y en la Ley 12/2012.

\subsection{Licencias urbanísticas en legislación estatal de suelo}

\subsubsection{Casos en que impone licencias}

La LS/15 parte de la competencia autonómica (art. 11.3: «Todo acto de edificación requerirá del acto de conformidad, aprobación o autorización administrativa que sea preceptivo, según la legislación de ordenación territorial y urbanística...»). Pero a continuación su art. 11.4 dispone:

«...serán expresos, con silencio administrativo negativo, los actos que autoricen:

a) Movimientos de tierras, explanaciones, parcelaciones, segregaciones $u$ otros actos de división de fincas en cualquier clase de suelo, cuando no formen parte de un proyecto de reparcelación.

b) Las obras de edificación, construcción e implantación de instalaciones de nueva planta.

c) La ubicación de casas prefabricadas e instalaciones similares, ya sean provisionales o permanentes.

d) La tala de masas arbóreas o de vegetación arbustiva en terrenos incorporados a procesos de transformación urbanística y, en todo caso, cuando dicha tala se derive de la legislación de protección del domino público».

La STC 143/2017, de 14 de diciembre, declaró inconstitucionales y nulas partes de las letras a) y d) (las transcritas en cursiva) y aceptó la constitucionalidad de las letras b) y c) aunque limitando su interpretación en los términos establecidos por su FJ 23. El precepto no pretendía tanto imponer licencias urbanísticas

nación del territorio, urbanismo (...) normas de construcción (...), que no regulan específicamente o no afectan específicamente a la actividad del servicio pero que tienen que ser respetadas por los prestadores en el ejercicio de su actividad económica al igual que por los particulares en su capacidad privada». A la larga, la tendencia a la reducción de autorizaciones sí que afecta en alguna medida a las licencias urbanísticas. Vid. M. DOMÍNGUEZ MARTíN, «La transformación del control local: de la licencia urbanística a la actuación comunicada», RDUyMA, núm. 311 (2017), págs. 105-106. Pero su fin encaja entre los siempre admitidos. Se justifican por lo que la Directiva de Servicios considera «razones imperiosas de interés general». Lo mismo hay que decir de la adecuación de su fin a las normas españolas aprobadas para su transposición (aunque sea una transposición radical) y a los más restrictivos de la LGUM [art. 17.1.b)]: en todo caso admiten autorizaciones para preservar el medio ambiente, el entorno urbano y el patrimonio histórico, fines de por sí suficientes para amparar las licencias urbanísticas. 
como proclamar el silencio negativo ${ }^{8}$. Y en la misma línea lo que se cuestionó la sentencia 143/2017 no es si el Estado puede establecer la necesidad de licencias urbanísticas sino si puede imponer el silencio negativo, lo que el TC sólo aceptó en parte. Pero implícitamente el art. 11.4 LS/15 comporta que el legislador estatal ha decidido no sólo que el silencio sea negativo sino que las actuaciones en él enunciadas (y no afectadas por la STC 143/2017) deben estar sometidas a licencia (o autorización similar). O sea, cabe decir, que el mismo Estado ha realizado un juicio de proporcionalidad y ha considerado que el sometimiento a licencia de esas actuaciones es proporcionado e impuesto a los legisladores autonómicos.

\subsubsection{Casos en los que expresamente permite la supresión de licencias}

En la misma LS/15 hay dos preceptos que abren la posibilidad de sustituir algunas de las clásicas licencias urbanísticas por declaraciones responsables o comunicaciones. Por un lado su art. 11.5 comienza diciendo: «Cuando la legislación de ordenación territorial y urbanística aplicable sujete la primera ocupación o utilización de las edificaciones a un régimen de comunicación previa o de declaración responsable...». Y ese mismo art. 11.5 termina afirmando que «la práctica de la comunicación previa a la Administración competente (...) deberán hacerse constar en el Registro de la Propiedad, en los términos establecidos por la legislación hipotecaria y por esta ley». Por otro lado, concordando con el anterior, el art. 28.1.b) LS/15 establece que para las escrituras de obra nueva terminada es necesaria autorización «salvo que la legislación urbanística sujetase tales actuaciones a un régimen de comunicación previa o declaración responsable». De estos dos preceptos se infiere que el legislador estatal, aun sin tomar él mismo la decisión, admite que se sustituyan ciertas licencias urbanísticas (concretamente, las de primera ocupación o utilización) por los medios de control más suaves. Ahora bien, de esos mismos preceptos se desprende que quien puede hacer esa sustitución es el legislador autonómico. En realidad, no hacía falta que la ley estatal permitiera esta sustitución de las licencias por declaraciones responsables o comunicaciones. Aunque no dijera nada, eso está en manos del legislador urbanístico, esto es, del autonómico. Si acaso lo que tendrá que hacer el Estado es adaptar su legislación sobre registros y documentos notariales a esa legislación autonómica. La afirmación entraña que las Comunidades Autónomas pueden suprimir las licencias urbanísticas (y sustituirlas en su caso por declaraciones o comunicaciones) no sólo en los casos expresamente contemplados por el legislador estatal (las de la primera ocupación o utilización) sino en cualquier otro salvo en los del art. 11.4 LS/2015.

En suma, la LS/15 comporta que hay actuaciones necesariamente sometidas a licencia sin que las Comunidades Autónomas puedan eximir de ellas; y que para las demás actuaciones (no sólo para la primera ocupación o utilización) el legislador autonómico puede suprimir las licencias urbanísticas en virtud de un juicio de proporcionalidad que a él corresponde. Por tanto, la legislación estatal del suelo no suprime ella misma ninguna licencia. Sólo hace guiños al legislador autonómico para que suprima las de primera ocupación o utilización.

\subsection{Las licencias urbanísticas en la Ley estatal $12 / 2012$}

\subsubsection{Actividades o establecimientos a los que afecta la Ley $12 / 2012$}

La restricción de autorizaciones tuvo repercusiones más concretas y relevantes en la legislación estatal por obra de la Ley 12/2012, de 26 de diciembre, de medidas urgentes de liberalización del comercio y de determinados servicios ${ }^{9}$, que, con retoques, está vigente y es capital para nuestro objeto. Parte de que las actividades a las que se refiere esa Ley estaban sometidas a licencia por algunas de las razones imperiosas de interés general que siguen justificando autorizaciones. Pero, pese a ello, las suprime por considerarlas

\footnotetext{
8 Proviene del Real Decreto-ley 8/2011, de 1 de julio, concretamente de su art. 23.1. En su preámbulo citaba la STS de 28 de enero de 2009 y explica que se trata de buscar «seguridad jurídica en el sector inmobiliario»: «Para ello, nada mejor que explicitar el carácter negativo del silencio en los procedimientos más relevantes de declaración de conformidad, aprobación o autorización administrativa en dichos ámbitos, lo que sin duda contribuirá a una mayor seguridad jurídica, impidiendo que la mera pasividad o inexistencia de actuaciones de actuaciones tempestivas de los Ayuntamientos permita entender a cualquier privado que le hayan sido concedidas licencias urbanísticas del más variado tipo».

9 Procede de la transformación en Ley del Real Decreto-ley 19/2012, de 25 de mayo. Sobre éste vid. M. C. NÚÑEZ LOZANO, "La transposición de la Directiva de Servicios en la ordenación del comercio. En especial, la previsión de autorizaciones, declaraciones responsables y comunicaciones", en M. REBOLLO PUIG (dir.), Derecho de la regulación económica, IX, Comercio interior, lustel, 2013 , págs. 539 a 543.
} 
desproporcionadas. Su art. 3 proclama la «inexigibilidad de licencia» y su art. 4 dispone su sustitución por «declaración responsable o comunicación previa». Eso es, en síntesis, lo que hace esta Ley ${ }^{10}$. Veamos con más detalle su repercusión sobre las licencias urbanísticas, que es lo que aquí interesa.

La Ley 12/2012 se aplica «a las actividades comerciales minoristas y a la prestación de determinados servicios previstos en el anexo de esta Ley, realizados en establecimientos permanentes, situados en cualquier parte del territorio nacional, y cuya superficie útil de exposición y venta al público no sea superior a 750 metros cuadrados» (art. 2.1).

La lista del Anexo se aumentó por Ley 14/2013 (43 actividades adicionales) hasta incluir actualmente 115 actividades. Se incluyen numerosos ramos del comercio minorista (hoy, prácticamente todos). Pero también muchas actividades de servicio: jurídicos, financieros, peluquerías, lavanderías, agencias de viaje, locutorios, de arquitectura, ingeniería, gestión administrativa, educación, pompas fúnebres, etc. Y, además, desde su redacción original -y más aún tras su reforma-, también aparecen algunas actividades industriales: ciertas industrias textiles y de cuero, de artes gráficas, de joyería y bisutería, etc. Quedan fuera, entre otras, la inmensa mayoría de las actividades turísticas, recreativas y de espectáculos tales como bares, restaurantes, discotecas, cines, teatros, salas de juego y similares ${ }^{11}$.

Aunque se habla de actividades, es determinante el concepto de establecimiento. Además, dice «establecimientos permanentes» ${ }^{12}$. Los establecimientos liberados son los que no superan cierta dimensión que se ha ido aumentando (Leyes 14 y 20/2013, lo que ha considerado constitucional la STC 79/2017, FJ 18): inicialmente era de 300 , luego de 500 y actualmente de 750 metros cuadrados (art. 2.1) ${ }^{13}$. Pero para el resto de establecimientos no se dice nada. Por ejemplo, para una tienda de 751 metros cuadrados nada preceptúa sobre si ha de quedar sometida a autorización ni por qué razones ni controlando qué requisitos.

\subsubsection{Licencias urbanísticas suprimidas por esta Ley: las de ciertas obras y las de utilización}

Las autorizaciones que se suprimen son descritas ampliamente en el art. 3: «Para el inicio y desarrollo de las actividades comerciales y servicios definidos en el artículo anterior, no podrá exigirse (...) la obtención de licencia previa de instalaciones, de funcionamiento o de actividad, ni otras de clase similar o análogas que sujeten a previa autorización el ejercicio de la actividad comercial a desarrollar o la posibilidad misma de la apertura del establecimiento correspondiente» (art. 3.1). Por tanto, la supresión de autorizaciones que impone no se circunscribe a las municipale ${ }^{14}$ y menos aún sólo a las urbanísticas. Pero, entre otras muchas, también éstas quedan afectadas ¿Cuáles concretamente?

10 Inicialmente no tipificaba infracciones ni preveía infracciones. Vid. B. LOZANO CUTANDA, "Ley 12/2012, de medidas urgentes de liberalización del comercio minorista y determinados servicios", Revista CESCO de Derecho del Consumo, núm. 5 (2013), pág. 213. Sólo tras la reforma que introdujo la Ley 5/2015 (que añadió un nuevo Capítulo III a la Ley 12/2012) se introdujo un régimen sancionador que, en cualquier caso, queda ahora al margen de nuestro objeto.

11 De entre los servicios recreativos, culturales y los relacionados con espectáculos y turismo lo único que sí cae dentro de la Ley 12/2012 son las bibliotecas y museos, así como la organización de congresos y la expedición de billetes para espectáculos públicos.

12 Por tanto, cuando se trate de establecimientos no permanentes no es de aplicación la Ley 12/2012. Pero no indica nada esta Ley sobre ese concepto de establecimiento permanente ni de lo que queda al margen de él. Tampoco indica el régimen de esos establecimientos no permanentes ni el de las actividades comerciales o de servicios que se desarrollen en ellos. Si quedan o no sujetos a licencias dependerá de lo que se deduzca del resto de la normativa.

${ }_{13}$ Pero nótese que lo que hay que computar es la «superficie útil de exposición y venta al público». Así que el establecimiento puede tener en realidad una dimensión superior a esos 750 metros cuadrados en tanto que, como es normal, haya espacios no dedicados a "exposición y venta al público». No hay reglas específicas para determinar qué ha de entenderse por tal superficie útil de exposición y venta al público. Sí las hubo en la legislación de comercio, pero a otros efectos, los de calcular los 2.500 metros cuadrados de los grandes establecimientos comerciales. Por ejemplo, art. 23 del Texto Refundido de la Ley de Comercio Interior de Andalucía que excluía, entre otros, los espacios destinados a almacén o aparcamiento. Pero es dudoso que este género de preceptos puedan utilizarse para interpretar el art. 2.1 de la Ley 12/2012. Además, el concepto mismo de "superficie útil de exposición y venta al público», que es apropiado para establecimientos de comercio minorista, es inadecuado para muchas de las actividades a que se refiere esta Ley y que no son de comercio minorista sino de servicios y hasta industriales, como hemos notado.

${ }_{14}$ Se proyecta sobre las más diversas autorizaciones que tuvieran por objeto las actividades a que se refiere esta ley, no sólo sobre las clásicas licencias municipales. Es cierto que alude expresamente a las «licencias de ámbito municipal» en su art. 1 y es indudable, desde luego, que éstas quedan incluidas en su ámbito de aplicación. Pero éste es más amplio como se deduce de todos los preceptos de la Ley, incluso de su art. 1 que, sólo tras referirse a todo género de «cargas y restricciones administrativas» se refiere «en particular» a la «supresión de las licencias de ámbito municipal». Entre las municipales que hay que entender afectadas están desde luego la tradicional de apertura y las ambientales. El Estado ha hecho él mismo un juicio de proporcionalidad y ha concluido que para todas las actividades incluidas en el ámbito de la Ley 12/2012 es excesiva -o sea, desproporcionada- la exigencia de tales autorizaciones y de todo cuanto tendían a controlar previamente sobre sus riesgos para la seguridad, la salubridad y la tranquilidad públicas y, en suma, para el medio ambiente. 
Por lo pronto, se suprimen y quedan prohibidas las licencias de obras que cumplan dos requisitos establecidos en el art. 3.3 de esta Ley 12/2012.

Primero, que se trate de «obras ligadas al acondicionamiento de locales para desempeñar la actividad comercial». Aunque eso es lo que dice el art. 3.3, hay que entender que se refiere a locales de menos de 750 metros cuadrados para desempeñar la actividad comercial o cualquier otra del Anexo, aunque sea de servicios o industrial ${ }^{15}$.

Segundo, que se trate de obras que «no requieran de la redacción de un proyecto de obra de conformidad con el art. 2.2 de la Ley 38/1999, de 5 de noviembre, de Ordenación de la Edificación» (en lo sucesivo, LOE). No importa si otras normas estatales, autonómicas o locales (incluidos los planes de urbanismo) exigen proyecto en otros casos: sólo los enumerados en el artículo 2.2 LOE son tenidos en cuenta a estos efectos. Si conforme a la LOE necesitan proyecto, necesitarán también licencia de obras. Pero si quedan fuera de estos supuestos quedan eximidas de licencia urbanística las obras ${ }^{16}$. Combinando el art. 3.3 de la Ley 12/2012 con el art. 2.2 LOE se colige que el supuesto más frecuente de exención de licencia de obras será el que, además de referirse a «obras ligadas al acondicionamiento de locales» para las actividades del Anexo de la Ley 12/2012, sean de intervención en edificios existentes que no alteren su configuración arquitectónica por no producir una variación esencial de la composición general exterior, la volumetría, o el conjunto del sistema estructural ni cambien los usos característicos del edificio.

A esos dos requisitos, añade la Ley 12/2012 otro de carácter negativo. Dice su art. 2.2 que «quedan al margen de la regulación (...) de esta Ley las actividades desarrolladas en los mencionados establecimientos que tengan impacto en el patrimonio histórico-artístico o en el uso privativo y ocupación de los bienes de dominio público». Muchas son las dudas que suscita esta norma. La primera y más importante se refiere al significado mismo de ese «quedar al margen» de esta Ley. Interpretado literalmente supone que en esos casos todo sigue igual: serán necesarias las licencias de apertura, las ambientales y cualesquiera que imponga la legislación sectorial; y, en concreto, serán necesarias siempre todas las licencias urbanísticas. Sin embargo, esa interpretación no es asumible: si la Ley parte, como explica su Preámbulo, de que son desproporcionadas ciertas autorizaciones por tratarse de actividades que no tienen peligrosidad suficiente ¿qué tiene el patrimonio histórico o el demanio para alterar ese juicio? Sólo los valores exclusivos e intrínsecos a esos bienes y son ésos únicamente los que tiene sentido controlar y preservar. Siendo así, la exclusión del régimen de la Ley $12 / 2012$ puede y debe ser más moderada. En cuanto a las que «tengan impacto (...) en el uso privativo y ocupación de los bienes de dominio público» por lo pronto hay que entender, aunque la Ley no lo diga exactamente así, que alude a las actividades que vayan a suponer un uso privativo o, cuando menos, un aprovechamiento especial del demanio (sea el de las vías o edificios públicos o el de las playas

15 Surge la duda de si sólo están eximidas las obras que se realizan inicialmente o si lo están también las que se acometan después para adecuar o adecentar el local. Dicho de otra forma: si lo están sólo las realizadas para la apertura y puesta en funcionamiento o también las que, con la misma escasa relevancia, se afronten después. Y ello ya sea para un establecimiento que, por el momento en que se abrió, sólo hizo declaración responsable o para el que, por llevar funcionando más tiempo, contó en su momento con licencia. El art. 1 de la Ley 12/2012 habla de «determinadas obras previas». Del Preámbulo de la Ley se deduce que lo que sobre todo le preocupa y lo que trata de atajar son los retrasos en la implantación de actividades que es lo que genera más dificultades para la creación y funcionamiento de las empresas. Por todo ello cabría sostener que las únicas obras liberadas de licencia son las iniciales, las que se producen para adecuar un local hasta ahora no utilizado o tras algún traspaso de negocio o cambio de ramo. Pero esa interpretación produce resultados poco lógicos. No se acertaría a comprender, por ejemplo, que la obra para hacer un modesto probador de ropa quede sometida a declaración responsable si se acomete al principio pero que necesitará licencia si se hace después. En suma, mejor es no distinguir para la misma obra en el mismo establecimiento según se haga al principio para abrirlo o se haga después para acomodarlo o adecentarlo.

16 Recuérdese que según el art. 2.2 de la Ley de Ordenación de la Edificación, en la redacción que le dio la Ley 8/2013, requieren proyecto técnico las siguientes obras: a) Obras de edificación de nueva construcción, excepto aquellas construcciones de escasa entidad constructiva y sencillez técnica que no tengan, de forma eventual o permanente, carácter residencial ni público y se desarrollen en una sola planta. b) Todas las intervenciones sobre los edificios existentes, siempre y cuando alteren su configuración arquitectónica, entendiendo por tales las que tengan carácter de intervención total o las parciales que produzcan una variación esencial de la composición general exterior, la volumetría, o el conjunto del sistema estructural, o tengan por objeto cambiar los usos característicos del edificio. Y c) Obras que tengan el carácter de intervención total en edificaciones catalogadas o que dispongan de algún tipo de protección de carácter ambiental o histórico-artístico, regulada a través de norma legal o documento urbanístico y aquellas otras de carácter parcial que afecten a los elementos o partes objeto de protección. Es amplia la exigencia de proyecto técnico. Por tanto, relativamente reducida la exoneración de licencia de obras que preceptúa el art. 3.3 de la Ley 12/2012. Y parece incluso que el siguiente art. 3.4 dice una obviedad cuando afirma que «la inexigibilidad de licencia que por este artículo se determina no regirá respecto de las obras de edificación que fuesen precisas conforme al ordenamiento vigente, las cuales se seguirán regulando, en cuanto a la exigencia de licencia previa, requisitos generales y competencia para su otorgamiento, por su normativa correspondiente». Incluso resulta desconcertante pues lo que dice resulta meridianamente del limitado ámbito en que suprime las licencias de obras que, desde luego, no cubre la las obras de edificación aunque lo sean para construir un local comercial de menos de 750 metros cuadrados. 
o las aguas...). Y, sobre esa base, lo que hay que añadir es que en tales casos será necesaria la autorización o concesión demanial que proceda conforme a la legislación de bienes de las Administraciones o la del concreto sector del dominio público afectado. Pero no que por ese sólo hecho queden sujetas a licencias urbanísticas de obras si, por las características de la actuación, no la precisan. Por tanto, cabe concluir que cuando se pretenda realizar actuaciones para las que la Ley 12/2012 excluye las licencias urbanísticas seguirá bastando a estos efectos la declaración responsable o la comunicación aunque será necesaria además la correspondiente concesión o autorización demanial. En cuanto al «impacto en el patrimonio históricoartístico ${ }^{17}$ habrá que estar a las leyes de las respectivas Comunidades Autónomas para concretar lo que entraña ese art. 2.2 de la Ley 12/2012; no sólo a sus respectivas leyes sobre patrimonio cultural sino también a las previsiones de sus leyes urbanísticas relativas sobre todo a planes especiales de protección de tales bienes y catálogos de inmuebles protegidos ${ }^{18}$. A lo sumo, lo que cabe añadir es que no tienen impacto en el patrimonio histórico las obras que, sin producirse sobre inmuebles individualmente protegidos sino sobre su entorno, no tengan relevancia exterior ni alteren ese entorno. Y quizá quepa también aceptar que en los casos en que sí sean necesarias esas autorizaciones el control administrativo para su otorgamiento debe quedar constreñido al cumplimiento de la legislación cultural y urbanística necesario para la preservación de los valores propios de ese patrimonio.

Además de las licencias de obras con el ámbito descrito, la Ley 12/2012 también suprime y prohíbe las licencias urbanísticas de utilización y de cambio de uso relativas a los establecimientos de su Anexo. Las licencias urbanísticas de utilización hay que entenderlas suprimidas desde luego en los mismos casos en los que se ha suprimido la licencia de obras. Pero, en realidad, también en los restantes casos, incluso cuando sí haya hecho falta licencia de obras, porque la licencia urbanística de utilización entra en la amplia descripción del art. 3.1 de la Ley 12/2012; como mínimo en su referencia genérica a las «similares o análogas» que sujetan el ejercicio de la actividad comercial a desarrollar o la posibilidad misma de la apertura del establecimiento correspondiente. Lo mismo hay que decir de las licencias de cambio de uso.

Igualmente hay que entender suprimidas otras licencias urbanísticas impuestas por la legislación autonómica. Piénsese, por ejemplo, en la «autorización de inicio de las obras» que prevén algunas legislaciones autonómicas ${ }^{19}$ : no es posible exigir ésta autorización para las obras amparadas por la Ley 12/2012. Es más, para ellas ni siquiera cabe sustituir aquella autorización por una comunicación o declaración responsable de inicio de las obras ${ }^{20}$.

\subsubsection{Posibilidad autonómica de eximir otras actuaciones de licencia y hasta de declaración responsable o comunicación}

Todo el régimen de la Ley 12/2012 es básico ${ }^{21}$. Por tanto, ha de ser respetado por las Comunidades Autónomas al ejercer cualquiera de sus competencias, aunque sean exclusivas, sobre cualquier materia.

17 La exigencia de licencia urbanística de obras en esos casos puede deducirse también del hecho de que en estos casos se exige proyecto técnico de acuerdo con el art. 2.2.c) LOE. Así que ello sumado al art. 3.3 de la Ley 12/2012 ya sería suficiente por sí para exigir licencia de obras.

18 Aplicándolo, por ejemplo, a la legislación andaluza hay que incluir sin duda todos los bienes inmuebles inscritos en el Catálogo General del Patrimonio Histórico Andaluz, sean de inscripción individual o colectiva o incluso cuando cuenten sólo con anotación preventiva (art. 6 de la Ley andaluza 14/2007). Englobemos también los inmuebles del Inventario de Bienes Reconocidos del Patrimonio Histórico Andaluz (art. 13 de la misma Ley). Tengamos en cuenta asimismo, puesto que se habla de «impacto en el patrimonio» y no precisamente de actuación sobre los bienes del patrimonio histórico, las intervenciones en el entorno de los bienes para evitar que los degraden o impidan o distorsionen su contemplación (arts. 19, 27.1 y 28 Ley 14/2007). Incluyamos asimismo los bienes de los catálogos urbanísticos (art. 16 Ley de Ordenación Urbanística de Andalucía) y, en general, los que tengan protección de cualquier modo por el planeamiento urbanístico por su valor histórico. En todos estos casos tan ampliamente delimitados lo que tiene sentido es que todas las obras -aunque estén ligadas al acondicionamiento de locales de menos de 750 metros cuadrados para desempeñar las actividades del Anexo de la Ley 12/2012- estén sujetas a las autorizaciones exigidas por la legislación de patrimonio histórico y por la urbanística.

19 Por ejemplo, art. 194.6 del TR de la Ley Foral de Ordenación del Territorio y Urbanismo y art. 301.2 del Reglamento de Urbanismo de Castilla y León aprobado por Decreto 22/2004.

20 Muchas razones justifican esta afirmación. Por lo pronto, si la comunicación o declaración responsable sustitutiva de la licencia de obras puede presentarse según la Ley 12/2012 el mismo día de comienzo de las obras y permite por sí misma acometerlas, es irracional que se exija otra comunicación o declaración para iniciarlas. Por otro lado, si aquí se parte de que no se ha dado licencia de obras es absurda una declaración cuyo contenido sería afirmar la coincidencia con tal licencia.

21 Lo declara su disposición final decimoprimera. Más aún: concede facultades al Gobierno para dictar normas que también tendrán carácter básico. No se trata de simples habilitaciones a su potestad reglamentaria (esto sólo está previsto para desarrollar el Título II de esta Ley que está por completo al margen de lo que nos ocupa). Se trata de deslegalizaciones por las que se autoriza al Gobierno a modificar algunos aspectos importantes de la Ley: el catálogo de actividades del Anexo (disposición final octava), el umbral 
También, pues, al regular el urbanismo ${ }^{22}$. Ahora bien, además de desarrollarla y completarla, la Ley permite a las Comunidades Autónomas «ampliar el umbral de superficie y el catálogo de actividades comerciales y servicios» del Anexo. Porque todo el régimen básico de la Ley 12/2012 es, como explica su Preámbulo, «sin perjuicio de que las Comunidades Autónomas, en el ámbito de sus competencias, puedan regular un régimen de mayor alcance en la eliminación de cualquier tipo de control previo». Por tanto, «mayor alcance» en la liberalización, no en el sometimiento a licencias ni controles preventivos. Y no sólo pueden aumentar la lista del catálogo o el umbral de superficie sino también establecer «regulaciones sobre estas mismas actividades con menor intervención administrativa» (disposición final décima), por ejemplo, permitiendo la libre realización de esas actividades sin ninguna carga formal previa, ni siquiera la de la comunicación ${ }^{23}$.

\section{LA SUPRESIÓN DE LICENCIAS URBANÍSTICAS EN LA LEGISLACIÓN AUTONÓMICA}

En el marco de la legislación estatal expuesta, las Comunidades Autónomas han adaptado su legislación urbanística y suprimido licencias ${ }^{24}$. Es difícil ofrecer un panorama que refleje fielmente la situación pues las legislaciones autonómicas son relativamente diversas. Pero, aun a riesgo de una simplificación excesiva y de alguna inexactitud, la situación puede sintetizarse así:

$11^{\circ}$ Todas las leyes autonómicas enumeran los supuestos en que es necesaria licencia. Algunas no admiten más supuestos que los establecidos en la misma ley ${ }^{25}$. Pero otras siguen aceptando que cualquier reglamento o los planes sometan a esa carga cualquier otra actuación ${ }^{26}$.

de superficie (disposición final novena) y el importe de las sanciones (disposición final decimotercera). Nunca ha hecho uso el Gobierno de estas deslegalizaciones que le permiten aumentar las actividades sin licencia (las modificaciones se han hecho por Decreto-Ley y por Ley). Pero si lo hiciera, la nueva regulación gubernamental tendría el mismo carácter básico.

22 Si una ley autonómica no respeta lo establecido en esta Ley 12/2012 incurrirá en inconstitucionalidad mediata. Y lo mismo cabe decir si se trata de reglamentos o actos administrativos. A este respecto el Preámbulo de la Ley 12/2012 afirma: «... por aplicación de la Ley 30/1992, de 26 de noviembre, de Régimen Jurídico de las Administraciones Públicas y el Procedimiento Administrativo Común, cualquier norma, disposición o acto, adoptado por cualquier órgano de las administraciones autonómicas o locales que contravenga o dificulte la aplicación de este régimen, podrá ser declarado nulo de pleno derecho, sin perjuicio de la exigencia, en su caso, de la correspondiente responsabilidad patrimonial a la Administración pública incumplidora». E igual que aquella Ley $30 / 1992$ permitía que cualquier ley consagrara nuevos supuestos de nulidad de pleno derecho de los actos administrativos [art. 62.1.g)], idéntica regla se contiene ahora en el art. 47.1.g) de su sucesora, la Ley 39/2015 de Procedimiento Administrativo Común. Lo extraño es que tal proclamación del Preámbulo no encuentra ningún reflejo en el articulado de la Ley 12/2012 (como tampoco lo encontraba en el Real Decreto-ley 19/2012, que está en su origen). No existiendo ningún precepto legal que prevea tal causa de nulidad, más bien cabe sostener que los actos administrativos contrarios a esta Ley $12 / 2012$ son sólo anulables. Sí que son nulos de pleno derecho todos los reglamentos (y planes) contrarios a esa Ley 12/2012 porque para ellos siempre se admite que su vulneración de las leyes es determinante del grado máximo de invalidez, esto es, de nulidad de pleno derecho (art. 47.2 LPAC, igual al anterior art. 62.2 de la Ley 30/1992). Sea como fuere, con anulabilidad o con nulidad, que no es eso lo importante, cualquier actuación administrativa (mediante reglamento, plan o acto) contraria a la Ley 12/2012 será inválida y así lo deberá declarar la jurisdicción contencioso-administrativa.

23 Cosa distinta es que, al margen de la Ley 12/2012, justamente en materia de urbanismo ese máximo de liberalización sí existe y se deriva, como ya nos consta, del LS/15; en concreto de su art. 11.4, que impone en ciertos casos la licencia urbanística, y de su art. 28.1.b) que impone para las escrituras de obra nueva que al menos se haya hecho comunicación. Por tanto, ni se pueden suprimir las licencias en aquellos casos ni se puede optar por excluir cualquier control previo en estos.

24 En realidad, ya antes de las leyes estatales expuestas, algunas leyes autonómicas urbanísticas preveían comunicaciones en lugar de algunas licencias. Vid. J. A. CHINCHILLA PEINADO, "El control municipal de los actos de uso del suelo y edificación a través de la figura de la comunicación previa como alternativa a la licencia urbanística. Análisis de la regulación legal y municipal y de la aplicación judicial”, RDUyMA, núm. 242 (2008), págs. 18 a 42. Pero ahora esa posibilidad es admitida mucho más ampliamente. Son excepción las Comunidades de Asturias, Cantabria y La Rioja que, salvo error, no han modificado sus respectivas leyes urbanísticas para prever expresamente ningún supuesto de declaración responsable o comunicación. Pese a ello, su legislación hay que entenderla desplazada para adecuarla, al menos, a la sustitución de licencias por comunicaciones o declaraciones impuesta por la Ley estatal 12/2012. Madrid, aunque no ha modificado su ley urbanística, aprobó la Ley 2/2012 de Dinamización de la Actividad Comercial que incorporó la Ley estatal 12/2012 y fue algo más lejos. Además, en su Ley del Suelo (Ley 9/2001), de manera oscura y desconcertante, hay elementos que apuntan a una cierta admisión de comunicaciones urbanísticas con la aberrante figura de la «licencia de actuación comunicada». Vid. J. A. CHINCHILLA PEINADO, "El control municipal...", cit., págs. 51-52; y A. M. NIETO-GUERRERO LOZANO, Licencia urbanística y comunicación previa de obras, Aranzadi, 2007, págs. 113 a 116.

25 Así, la Ley 2/2016 del Suelo de Galicia enumera de forma taxativa las actuaciones sujetas a licencia (art. 142.2). Igual es la Ley 13/2015 de Ordenación Territorial y Urbanística de la Región de Murcia (art. 263.2). Y similar es la Ley 4/2017 del Suelo y los Espacios Protegidos de Canarias que termina su enumeración de actuaciones sometidas a licencia con esta cláusula: «la realización de cualquier otra actuación que en la presente ley se someta al régimen de licencia urbanística» (art. 330.1.t)].

${ }^{26}$ La Ley valenciana 5/2014 de Ordenación del Territorio, Urbanismo y Paisaje, art. 213.t), termina su lista de actuaciones sometidas con este añadido: "Todas las demás actuaciones en que lo exija el planeamiento o las ordenanzas municipales». A la misma idea responde la Ley 12/2017 de Urbanismo de la las Islas Baleares, art. 146.1.p). En Andalucía el art. 169.1.g) de su Ley de 
REALA. Nueva Época - N. ${ }^{0}$ 11, Abril-Septiembre 2019 - ISSN: 1989-8975 - DOI: 10.24965/reala.v0i11.10655 - [Págs. 6-28]

De las licencias urbanísticas a las declaraciones responsables

Manuel Rebollo Puig

2. ${ }^{\circ}$ En general, son las mismas leyes las que deciden qué licencias se sustituyen por comunicación o declaración. Pero algunas atribuyen en parte a los Ayuntamientos esta decisión ${ }^{27}$.

$3 .^{\circ}$ La supresión de licencias ha supuesto en general su sustitución por otra carga formal previa (comunicación o declaración responsable). Pero en algún caso se ha establecido expresamente que ciertas actuaciones no requieren nada de ello ${ }^{28}$.

4. ${ }^{\circ}$ Al suprimir licencias urbanísticas, optan por sustituirlas bien por declaraciones responsables bien por comunicaciones ${ }^{29}$. Pero algunas se sirven de las dos figuras ${ }^{30}$.

$5 .^{\circ}$ Suelen establecer que las declaraciones o comunicaciones pueden ser simultáneas al inicio de la actuación ${ }^{31}$. Pero algunas leyes autonómicas exigen su presentación con cierta antelación ${ }^{32}$.

6. ${ }^{\circ}$ Respecto a las obras, su sujeción a comunicación o declaración responsable en vez de a licencia tiene diversa amplitud. Alguna Comunidad Autónoma se quedan en el mínimo: lo que impone la Ley estatal

Ordenación urbanística [reiterado por el art. 8.q) de su Reglamento de Disciplina Urbanística] permiten que sus ya largas listas de actuaciones sometidas a licencia sean ampliadas por planes generales $u$ otros reglamentos. Por su parte el art. 226.2.g) del Texto Refundido de la Ley de Urbanístico de Aragón (Decreto Legislativo 1/2014) se refiere a «otros supuestos establecidos en el plan general por concurrir razones especiales de interés público que habrán de especificarse en la memoria». El art. 207.1 de la Ley vasca 2/2006 de Suelo y Urbanismo termina su enumeración de los actos sujetos a licencias con «cualquier otro que señalen los instrumentos de planeamiento de ordenación territorial y urbanística». Igual son los arts. 165.1.t) y 169.1.c) del TR de Castilla-La Mancha. El art. 151.1.t) de la Ley del Suelo de Madrid (Ley 9/2001) se refiere a «los demás actos que señalen los instrumentos de planeamiento urbanístico».

27 El ejemplo extremo lo ofrece el País Vasco. Su Ley 2/2006 de Suelo y Urbanismo sigue sometiendo todas las actuaciones a licencia y en ningún caso la sustituye por declaración o comunicación. Pero su art. 207.5 (tras la reforma operada por Ley 7/2012) dispone: «Las ordenanzas municipales podrán sustituir la necesidad de obtención de licencias por una comunicación previa (...) cuando se trate de la ejecución de obras de escasa entidad técnica, para las cuales no sea necesaria la presentación de proyecto técnico, o para el ejercicio de actividades que no tengan la condición de molestas, insalubres, nocivas o peligrosas, y para aquellas otras actuaciones que prevean las propias ordenanzas». Más frecuentemente, las Comunidades Autónomas han optado por sustituir ellas mismas las licencias por declaraciones y comunicaciones, pero permitiendo a los Ayuntamientos aumentar esa sustitución. Por ejemplo, el Decreto Foral Legislativo 1/2017 sujeta a declaración o comunicación ciertas actuaciones y «aquellas obras de escasa entidad o dimensión que se determinen en las ordenanzas municipales correspondientes» [art. 192.1.b)]. En Baleares esto se presenta con una singularidad: se permite eso, no a los Ayuntamientos, sino a los Consejos Insulares y, además, en supuestos relativamente reducidos [por ejemplo, no pueden hacerlo para «la primera ocupación de las edificaciones de nueva planta», art. 148.1.h)]. En Aragón, esa facultad municipal estaba reconocida con carácter general en su Ley de Administración Local. Concretamente, su art. 194 bis, según la redacción que le dio el Decreto-Ley 1/2010, dice que «las entidades locales, salvo que una ley sectorial establezca lo contrario, podrán prever en sus ordenanzas la sustitución de la necesidad de obtención de licencia por una comunicación o declaración responsable (...) cuando se trate del acceso a una actividad de servicios y su ejercicio u otras actuaciones previstas en dichas ordenanzas». Es dudoso que se pueda aplicar a las licencias urbanísticas. En Cataluña esa posibilidad municipal estaba prevista en el art. 71.2 del Reglamento de Protección de la Legalidad Urbanística (Decreto 64/2014 que concordaba con el art. 187.4 de su Ley), pero acaso esa previsión reglamentaria haya quedado desfasada tras la Ley catalana 16/2015. Vid. M. VAQUER CABALLERÍA, "La licencia de obras", en L. PAREJO ALFONSO (dir.), Autorizaciones y licencias, hoy, Tirant lo Blanch, Valencia, 2013, págs. 54-55.

${ }^{28}$ Así, la Ley 4/2017, de 13 de julio, de Espacios Protegidos y Espacios Públicos de Canarias establece las denominadas «actuaciones exentas» que se permiten realizar sin licencia ni declaración ni comunicación. Entre otras, se incluyen aquí el arreglo de las instalaciones vinculadas a la agricultura, la reparación de muros en suelo agrícola y, sobre todo, «las obras de conservación o reforma consistentes en la sustitución de acabados interiores de una vivienda o local, como solados, alicatados, yesos y pinturas, cuando no estén protegidos arquitectónicamente, todo ello sin perjuicio de contar con las autorizaciones necesarias para la retirada de residuos inertes» (art. 333).

${ }_{29}$ Se habla de declaración responsable en la legislación urbanística de Aragón, de Castilla y León, de la Comunidad Valenciana. Por el contrario, en la legislación urbanística de Baleares, Canarias, Castilla-La Mancha, Cataluña, Extremadura y Galicia se exigen comunicaciones. Habla de «declaración responsable o comunicación previa», sin decidirse por una figura o la otra o como si fuesen expresiones sinónimas, el Decreto Foral Legislativo 1/2017 (arts. 192 y 195).

El Texto Refundido aragonés, por una parte establece las actuaciones sujetas a declaración responsable (art. 227.2) y, por otra, se refiere a la «comunicación previa en materia de urbanismo» (art. 228), pero no señala ningún supuesto.

30 Así, la Ley murciana 13/2015, de 30 de marzo, de Ordenación Territorial y Urbanística: declaraciones responsables para ciertos actos (art. 264.2) y comunicaciones para otros (art. 265). Igualmente, el Texto Refundido de Urbanismo de Aragón (Decreto Legislativo 1/2014) distingue entre «declaración responsable en materia de urbanismo» (art. 227) y "comunicación previa en materia de urbanismo» (art. 228). Enumera taxativamente las actuaciones sujetas a la primera y dice que cualquier otra actuación no sometida ni a licencia ni a declaración responsable requerirá comunicación previa.

31 V. gr., art. 238.4 TR de Aragón; art. 222.3 Ley valenciana; art. 158.1 TR de Castilla-La Mancha tras la reforma por Ley 1/2013; art. 266.2 de la Ley murciana.

${ }^{32}$ Por ejemplo, en las de Canarias, Extremadura y Galicia quince días antes del inicio de las obras o actuación. Aunque para hacerlo más complicado en algunas Comunidades son días naturales y en otras días hábiles. En Baleares se exige según los casos uno o quince días. En Cataluña, según su Reglamento de Protección de la Legalidad Urbanística (Decreto 64/2010), la regla general es que la comunicación permite la realización inmediata del acto; pero hay excepciones como la relativa a la comunicación de primera utilización y ocupación que debe realizarse con antelación de un mes (arts. 72.3 y 75.2). 
12/2012 y nada o poco más. Ejemplo diáfano de ello es el de Andalucía ${ }^{33}$ pero con menos claridad responden al mismo modelo otras Comunidades ${ }^{34}$. En el extremo opuesto, quizá la que haya llegado más lejos sea Murcia cuya Ley 13/2015 de Ordenación Territorial y Urbanística sólo impone licencia en los casos establecidos en la legislación básica estatal y muy poco más (art. 263.2) ${ }^{35}$. Entre uno y otro modelo, las leyes autonómicas ofrecen soluciones intermedias. Frecuente es que sometan a comunicación o declaración responsable las obras de conservación, restauración, mantenimiento o reparación que no afecten a elementos estructurales ${ }^{36}$. En Aragón, a eso se añaden las «obras de edificación de nueva planta de escasa entidad constructiva y sencillez técnica que no tengan, de forma eventual o permanente, carácter residencial ni público y se desarrollen en una sola planta» [art. 227.2.a) de su Texto Refundido]. Finalmente, algunas Comunidades hacen depender la exigencia de licencia de que las obras requieran proyecto técnico ${ }^{37}$.

${ }_{33}$ Andalucía, sin modificar ni un solo artículo de su Ley 7/2002 de Ordenación Urbanística, le añadió por Ley 3/2014, una disposición adicional $14 .^{\text {a }}$ en la que para «el ámbito de aplicación de la Ley 12/2012, de 26 de diciembre», dice: «...no será exigible licencia o autorización previa para la realización de las obras ligadas al acondicionamiento de los locales para desempeñar la actividad económica cuando no requieran de la redacción de un proyecto de obra de conformidad con el art. 2.2 de la Ley 38/1999, de 5 de noviembre, de Ordenación de la Edificación. En esos casos, será sustituida por la presentación de una declaración responsable o bien por una comunicación previa».

${ }^{34}$ En Castilla-La Mancha los únicos casos que expresa y claramente quedan sometidos a comunicación son los de «obras necesarias para el acondicionamiento de los establecimientos en los que se pretendan implantar las actividades señaladas en la letra anterior (son en suma las de la Ley estatal 12/2012) cuando no requieran la presentación de un proyecto de obras» (art. 157 del Texto Refundido de la Ley de Ordenación del Territorio y de la Actividad Urbanística, aprobado por Decreto Legislativo 1/2010, tras la reforma por Ley 1/2013). En otras Comunidades hay también alusiones a lo previsto en esa Ley 12/2012 pero ello unido a otros supuestos. Por ejemplo, en la Ley extremeña del Suelo y Ordenación del Territorio (Ley 15/2001, tras reforma por Leyes 12/2010 y 10/2015) se somete a comunicación «la apertura de establecimientos permanentes en los que se desarrollen actividades comerciales cuya superficie útil de exposición y venta al público no sea superior a 750 metros cuadrados y siempre que no supongan un impacto sobre el patrimonio histórico-artístico o sobre el uso privativo y ocupación de bienes de dominio público» [art. 172.1.f)]. Además de eso, en esta Ley extremeña sólo se prevé comunicación para «las obras de mera reforma y las que modifiquen la disposición interior de las edificaciones o construcciones, cualquiera que sea su uso que no requieran la redacción de un proyecto por no alterar su configuración arquitectónica ni supongan impacto sobre el patrimonio histórico-artístico o sobre el uso privativo y ocupación de bienes de dominio público» [art. 172.1.a)]. En la legislación navarra quedan sujetas a declaración responsable «la realización de obras ligadas al acondicionamiento de los locales para desempeñar la actividad comercial de conformidad con la normativa sectorial...» [art. 192.1.a) del Decreto Foral Legislativo 1/2017].

${ }^{35}$ En esa Ley murciana 13/2015 basta declaración responsable para las «obras de ampliación, modificación, reforma, rehabilitación o demolición sobre edificios existentes cuando no produzcan una variación esencial de la composición general exterior, la volumetría, la envolvente total o el conjunto del sistema estructural, o cuando no tengan por objeto cambiar los usos característicos del edifico», así como la «renovación de instalaciones en las construcciones» (art. 264.2). Asimismo somete a declaración responsable «de conformidad con la legislación básica estatal (...) la realización de obras de acondicionamiento de locales para desempeñar actividades de comercio minorista y de prestación de servicios cuando no requieran la presentación de un proyecto de obras» (art. 264.3). Y es suficiente comunicación para las «obras menores», esto es, «aquéllas que por su escasa entidad constructiva y económica y sencillez en su técnica no precisan ni de proyecto técnico ni de memoria constructiva consistiendo normalmente en pequeñas obras de simple reparación, decoración, ornato o cerramiento» (art. 265.2).

${ }^{36}$ Por ejemplo, en Castilla y León requieren únicamente declaración responsable (arts. 105 bis de la Ley 5/1999, modificada por Leyes 4/2008 y 7/2014, y 314 bis de su Reglamento): las obras de modificación, reforma o rehabilitación de construcciones e instalaciones, cuando tenga carácter no integral o parcial; las obras de mantenimiento y reparaciones puntuales del edificio; las obras e instalaciones en el subsuelo, cuando no tengan entidad equiparable a las obras de nueva planta o ampliación ni afecten a elementos estructurales; y las obras menores tales como sustitución, renovación o reparación de revestimientos, alicatados, pavimentos, falsos techos, carpintería interior, fontanería, instalaciones eléctricas, enlucidos y pinturas, así como los trabajos previos a la construcción, tales como sondeos, prospecciones, catas... Vid. M. A. GONZÁLEZ BUSTOS, «Simplificación administrativa, licencias urbanísticas y declaración responsable», Revista Jurídica de Castilla y León, núm. 39 (2016), págs. 19 a 21. En la misma dirección está la Ley valenciana $5 / 2014$, aunque también sujeta sólo a declaración responsable las obras «de modificación o reforma que afecten a la estructura o al aspecto exterior e interior de las construcciones, los edificios y las instalaciones de todas clases, cualquiera que sea su uso, que no supongan ampliación ni obra de nueva planta». Asimismo, art. 332.1 de la Ley canaria 4/2017, requieren comunicación: a) las obras de conservación, restauración, reforma, rehabilitación o reestructuración de edificaciones e instalaciones, siempre que no afecten a edificios catalogados ni incrementen volumen ni edificabilidad; $y$ b) las obras exteriores en edificios no catalogados, salvo que se refieran a la modificación general de fachada o al acristalamiento de terrazas existentes mediante un proyecto conjunto de fachada.

37 Por ejemplo, en la legislación gallega (Ley 2/2016 y Reglamento aprobado por Decreto 143/2016) se someten a comunicación «los actos de edificación (...) que, conforme a la normativa general de ordenación de la edificación, no precisen de proyectos de obras de edificación». Igualmente en Cataluña necesitan sólo comunicación «las construcciones e instalaciones de nueva planta y las obras de ampliación, reforma, modificación, rehabilitación o demolición total o parcial de construcciones e instalaciones existentes que, de acuerdo con la legislación sobre ordenación de la edificación, no requieren la elaboración de un proyecto técnico» [art. 187 bis.a) del Texto Refundido de Ley de Urbanismo tras su reforma por Ley 16/2015]. Aunque la Ley balear 12/2017 de Urbanismo también alude a la necesidad de proyecto técnico, en realidad es más restrictiva: somete a licencia casi todo lo que tradicionalmente la ha requerido. Lo que sujeta directamente a comunicación son «las obras de técnica sencilla y entidad constructiva escasa u obras de edificación que no necesiten proyecto, de acuerdo con la Ley 38/1999, de 5 de noviembre, de ordenación de la edificación», así como «la instalación de placas solares (...) sobre la cubierta de los edificios y las instalaciones de puntos de recarga para vehículos eléctricos...» (art. 148.1 y 4 ). 
7. Además de algunas licencias de obras, varias Comunidades Autónomas han sustituido las licencias de ocupación, utilización o cambio de uso por comunicaciones o declaraciones responsables ${ }^{38}$. Pero otras mantienen tales licencias ${ }^{39}$.

8. Algunas Comunidades Autónomas han instaurado la comunicación o declaración responsable para otras actuaciones que ellas mismas habían sujetado antes a licencia; ejemplo concreto es el del inicio de obras, antes sometido a licencia y ahora a declaración responsable ${ }^{40}$.

9. Sea amplia o reducida la sustitución de licencias urbanísticas por comunicaciones o declaraciones, hay notable diversidad e imprecisión sobre el contenido de esos escritos y sobre la documentación que debe adjuntarse, aunque se detecta cierta tendencia a recargarlos.

$10{ }^{\circ}$ En general, esa sustitución de licencias urbanísticas por comunicaciones o declaraciones no se ha completado con una regulación esmerada que adecue las potestades de disciplina urbanística a la nueva implantación de esas figuras.

Ante este panorama dedicaremos las siguientes páginas a sugerir líneas de reforma tanto en lo que se refiere a la extensión de cada género de control previo como a su concreto contenido. Dejaremos para otra ocasión las propuestas sobre el régimen de disciplina urbanística que debería acompañar a la instauración de comunicaciones o declaraciones responsables y que, como hemos dicho, ha sido descuidado por la legislación urbanística autonómica ${ }^{41}$.

\section{PROPUESTA SOBRE EL ALCANCE DE LA SUPRESIÓN DE LICENCIAS URBANÍSTICAS}

\subsection{Debe ser la ley la que decida las actuaciones sujetas a licencia, a comunicación o a declaración responsable}

Ya dijimos que en nuestro ordenamiento son las normas con rango de ley las que pueden someter actuaciones privadas a la necesidad de autorización. Aunque esté establecido menos claramente, también deben ser las normas con rango de ley las que sujeten a comunicación o a declaración responsable las actuaciones privadas ${ }^{42}$. En cualquier caso, sea o no necesaria una ley, ésa es la mejor solución para que sea

38 Así sucede en Aragón [art. 227.2.d)]; Castilla y León [art. 105 bis.1.b) de la ley 5/1999, tras las reformas introducidas por Leyes 4/2008 y 7/2014]; Canarias [art. 332.1.c)], que también se refiere expresamente al cambio de uso de edificios e instalaciones [art. 332.1.d)]; Cataluña: concretamente se sujeta a comunicación «la primera utilización y ocupación de los edificios» y «el cambio de uso de los edificios y las instalaciones, salvo a uso residencial» [art. 187 bis b) y c) del Texto Refundido de la Ley de urbanismo tras reforma por Ley 16/2015].; Murcia: somete a declaración responsable la «primera ocupación de edificaciones de nueva planta y sucesivas ocupaciones en edificios existentes» [art. 264.2.c) de la Ley 13/2015].. Ejemplo de esta regulación es el art. 214.d) de la Ley valenciana 5/2014 que somete a declaración responsable «la primera ocupación de las edificaciones y las instalaciones, concluida su construcción (...) así como el segundo y siguientes actos de ocupación de viviendas». Sin embargo, esta Ley valenciana exige licencia para «la modificación del uso de las construcciones, edificaciones e instalaciones, así como del vuelo sobre los mismos» [art. 213.g)]. En Galicia quedan expresamente sujetas a comunicación el uso del suelo y subsuelo cuando previamente haya habido obras de las que no requieren proyecto; «la utilización del suelo para el desarrollo de actividades mercantiles, industriales, profesionales, de servicios u otras análogas»; «el uso del vuelo sobre las edificaciones e instalaciones de cualquier clase»; y «la modificación del uso de parte de los edificios e instalaciones, en general, cuando no tengan por objeto cambiar los usos característicos del edificio ni implantar un uso residencial» (art. 360 del Reglamento).

39 Ejemplo claro es el de Baleares. Su Ley 12/2017 somete a licencia «la primera ocupación o utilización de los edificios y las instalaciones en general» [art. 146.1.m)]. Andalucía las mantiene igualmente [arts. 169.1.e) de su Ley de Ordenación Urbanística y 8.e) de su Reglamento de Disciplina Urbanística]. Por su parte, Extremadura sólo ha asumido esa sustitución muy limitadamente. Lo que su Ley del Suelo y Ordenación Territorial sujeta sólo a comunicación es la «modificación de usos de los edificios, construcciones e instalaciones cuando no se sujete a licencia urbanística». Pero su art. 184 exige licencia para: a) La primera ocupación, total o parcial, de los edificios residenciales de nueva planta y de las casas prefabricadas y similares, provisionales o permanentes; b) La primera utilización, total o parcial, de los edificios, construcciones e instalaciones de nueva planta....; d) La modificación del uso de los edificios, construcciones o instalaciones cuando comporten obras sujetas a licencia urbanística conforme al art. 180 o, en todo caso, la modificación del uso característico o mayoritario".

${ }^{40}$ Es lo que ha sucedido en Andalucía. La autorización de inicio de obras se impuso en el art. 21 de su Reglamento de Disciplina Urbanística de 2010 para otorgarse ya a la vista del proyecto de ejecución y si se comprobaba que no había alterado el proyecto básico tenido en cuenta para dar la licencia de obras. Por Decreto andaluz 337/2012 se modificó aquél art. 21 para, según su preámbulo, proceder a una simplificación «mediante la sustitución de la autorización de inicio de las obras por una declaración responsable». En realidad, es una verdad a medias porque la autorización de inicio de obras sigue siendo necesaria cuando hay cualquier variación, incluso insustancial, respecto al proyecto básico.

41 Vid. "Disciplina urbanística y declaraciones responsables", REDA, 2019 (en prensa).

42 De este aspecto crucial se han ocupado M. C. NUÑEZ LOZANO, "Aproximación al régimen jurídico de las declaraciones responsables y las comunicaciones", cit., pág. 117; y J. M. TRAYTER JIMÉNEZ, "Declaraciones responsables, comunicaciones previas 
el legislador el que haga el juicio de proporcionalidad que late en esas opciones. Lo ideal es que lo haga sin remisiones a reglamentos, ordenanzas o planes; sobre todo sin remisiones abiertas e incondicionadas a esa regulación administrativa. Por eso como primer paso deben desaparecer los preceptos que remiten a los planes el sometimiento a licencia de actuaciones. No debe haber tal remisión a los planes generales ${ }^{43}$ ni a ningún otro (tampoco a los de ordenación del territorio) ni a los reglamentos autonómicos ni locales. Y tampoco debe haber regla similar ahora para decir que sean los planes o los reglamentos los que determinen las actuaciones sujetas a declaración responsable o comunicación. Por tanto, también es desaconsejable la opción de algunas leyes autonómicas (balear, navarra, vasca) que permiten a los entes locales determinar el ámbito de las licencias y de las comunicaciones o declaraciones. Todo eso debe estar decidido en norma con rango de ley y de manera uniforme. No tiene sentido que el juicio de proporcionalidad sobre la necesidad de licencias, comunicaciones o declaraciones arroje resultados diferentes en cada municipio. Además ello es inconveniente para la seguridad jurídica y la actividad empresarial que requieren reglas de mayor ámbito territorial, como mínimo el autonómico.

\subsection{Propuesta de supresión de concretas licencias urbanísticas}

La solución mínima (o sea, la de reducir la sustitución de licencias por declaración o comunicación a los casos que impone la Ley estatal 12/2012) no es de recibo. Ni satisface el principio de proporcionalidad (en realidad significa que el legislador autonómico no se ha molestado en hacer ningún juicio de proporcionalidad) ni produce resultados razonables. Nadie comprenderá que para hacer una modesta obra con la finalidad de adaptar un local comercial no se exija licencia pero que para hacer idéntica obra en una vivienda o en un bar o en un hotel sí sea necesaria. Incluso cabe cuestionar la racionalidad de la supresión de licencias de obras sólo para los locales del anexo de la Ley 12/2012 cuando tengan menos de 750 metros cuadrados: ese umbral puede tener sentido para valorar su incidencia sobre el medio ambiente o sobre otros intereses públicos; pero es irracional que la exigencia o no de licencia de obras se haga depender del tamaño del local y no de la envergadura y relevancia urbanística de las obras. Y como quiera que la Ley 12/2012 no sólo afecta a las licencias de obras sino también a las de ocupación, utilización y cambio de uso, similares valoraciones cabe hacer respecto a éstas cuando se refieran a actividades distintas de las del anexo de tal Ley. Es explicable que el Estado, que sólo pretendía una cierta liberalización económica, se centrara en las obras de adaptación para ciertos establecimientos mercantiles. Pero no es justificable que la Comunidad Autónoma no extienda tal exención de la licencia como mínimo a obras similares, para actividades no comprendidas en la Ley 12/2012 (viviendas, actividades recreativas o turísticas, por ejemplo).

La solución máxima (es decir, la de exigir licencias urbanísticas sólo en los casos en los que la legislación estatal las impone, esto es, los del art. 11.4 LS/15) tampoco es aceptable, máxime tras la STC 143/2017 (esto es, la que ha anulado parte del art. 11.4 LS/15): parece excesiva o, como mínimo, imprudente.

\footnotetext{
y derechos de los ciudadanos", en M. REBOLLO PUIG, M. LÓPEZ BENÍTEZ y E. CARBONELL PORRAS (coords.), Régimen jurídico básico de las Administraciones Públicas. Libro Homenaje al Profesor Luis Cosculluela, lustel, 2015, pág. 519. Según NúÑEZ es necesaria una habilitación legal aunque «debe entenderse de un modo flexible». Para TRAYTER existe una reserva de ley y es contrario al sistema «establecer nuevas comunicaciones previa o declaraciones responsables en materias o sectores del ordenamiento que antes no preveían licencia o autorización y, además, que esta operación se haga sin una Ley previa de cobertura». Según creo, se deduce esa respuesta del principio de legalidad administrativa como vinculación positiva a la ley para todo aquello que suponga límites a la libertad genérica de los ciudadanos; principio en cuya virtud la Administración no puede imponer deberes o restricciones a los ciudadanos nada más que si cuenta con una habilitación legal para ello. No puede hacerlo ninguna Administración, tampoco las locales. No puede hacerlo por ningún medio, especialmente no puede hacerlo por reglamento o, en el ámbito, local, por ordenanza. Imponer que para abordar una actividad privada fruto del ejercicio de la libertad genérica de los ciudadanos o incluso de algún derecho fundamental (tales como la libertad de empresa y la propiedad) el sujeto debe comunicarlo a la Administración con más o menos concreción y manifestaciones complementarias también es una limitación; una limitación menos gravosa que la de la autorización, pero una limitación a fin de cuentas. Una limitación que consiste en esto: está prohibido ejercer una actividad (y ejercer un derecho) mientras no se haga una comunicación o declaración ante la Administración. Y, por ello, conforme a aquella vinculación positiva a la ley, tal sujeción sólo la puede hacer directamente la ley o, si acaso, hacerla la Administración (mediante reglamento, incluidas las ordenanzas) si cuenta con habilitación legal concreta que acote bien sus posibilidades.

${ }^{43}$ Lo que a los planes debe corresponder es la ordenación urbanística del término municipal, no inventar regímenes jurídicos: igual que no tiene sentido confiarles los sistemas de restablecimiento de la legalidad, tampoco lo tiene atribuirles la determinación de los supuestos sometidos a licencia o a otras cargas alternativas. Lo que sí puede aceptarse es una habilitación a los planes más modesta para que concreten los casos ya determinados por la ley. Por ejemplo, sí que pueden ser los planes, atendiendo a sus concretas previsiones de ordenación, los que especifiquen cuándo se deberá considerar que hay cambio de uso para que sólo sea tal y sólo quede sometido a cargas formales el que tenga alguna relevancia a la vista de las atribuciones de uso hechas en el mismo plan. Pero esto es completamente distinto de permitirles que decidan qué género de actuaciones necesitarán licencias, declaraciones o comunicaciones o nada.
} 
También aquí in medio virtus. Y dentro de las soluciones intermedias, elegir la que se pueda formular de manera sencilla. Con ese propósito osaré hacer una concreta propuesta.

\subsubsection{Obras}

En cuanto a las obras, podrían liberarse de la licencia todas las que, conforme a la Ley de Ordenación de la Edificación, no necesitan proyecto técnico. O sea, dicho positivamente, que sea necesaria licencia siempre que sea necesario proyecto técnico conforme al art. 2.2 LOE; y sólo en tales casos ${ }^{44}$. Dadas las enormes dificultades que en la práctica se presentan para demoler las construcciones ilegales, cabe afirmar que la exigencia de licencia en esos casos es proporcionada puesto que otras formas de control llegarían demasiado tarde para ser realmente efectivas. Por el contrario, para las modestas obras que no requieren proyecto técnico, su sometimiento a licencia es desproporcionado ${ }^{45}$.

Con la regla propuesta, desde luego, se daría cumplimiento a la Ley 12/2012. Todas las obras a las que se refiere esa Ley estatal quedarían eximidas de licencia de obras sin necesidad de una mención especial pues todas ellas son de las que no requieren proyecto técnico. Pero habría otras muchas no amparadas por esa Ley 12/2012 con igual liberación.

No sería imprescindible aclarar que si el edifico afectado por la obra tiene algún grado de protección por la legislación de patrimonio cultural o por la planificación urbanística sí que sería necesaria licencia pues, en realidad, ello se desprende del art. 2.2.c) LOE que para tales casos exige proyecto técnico. Aun así, sería conveniente concretarlo: afirmar en la Ley que toda obra en edificios protegidos por la legislación de patrimonio cultural o la urbanística necesita licencia; y añadir que, aunque el edificio no cuente con tal protección individual, cuando se encuentre en conjuntos o entornos protegidos la necesitarán pero sólo si la obra tiene relevancia exterior.

Tampoco sería necesario añadir nada para los casos en que la obra afecte a cualquier bien demanial. Tales supuestos estarán necesitados de concesión o autorización demanial o, si ya se cuenta con ella y no suponen más utilización del dominio público, requerirán para cualquier alteración el consentimiento de la Administración titular del bien. Pero ello nada tiene que ver con el urbanismo ni con la finalidad de sus licencias ni dependerá en todo caso del Ayuntamiento sino de la Administración titular del concreto bien de que se trate. A este respecto ni siquiera tiene sentido distinguir entre bienes demaniales y patrimoniales de cualquier Administración. La titularidad de los bienes afectados por una obra plantea cuestiones que nada tienen que ver con el urbanismo. Si acaso lo que tendría que quedar claro es que la exoneración de la licencia urbanística no exime del deber de contar con los títulos que exija la legislación sobre bienes de que en cada caso se trate.

Todo esto debería completarse con la supresión completa de la autorización del inicio de obras. No ya sólo en los casos en que no se exija previamente la licencia ordinaria de obras sino en todos los casos. Y seguramente ni siquiera convenga sustituir esa autorización por una declaración responsable ${ }^{46}$.

${ }^{44}$ Seguramente cabe hacer algunos reparos a esa propuesta; por ejemplo, cabe decir que el hecho de que se exija o no proyecto técnico, aunque revela la intensidad de los problemas constructivos de la obra, no siempre refleja su relevancia urbanística. Aun así, sí que hay normalmente una relación entre esos dos factores (complejidad constructiva y relevancia urbanística) y, además, es un criterio manejado por el legislador estatal (Ley 12/2012) y por algunos autonómicos (Galicia y Cataluña). Además, no puede dejar de reconocerse que el art. 2.2 LOE tiene varios conceptos jurídicos indeterminados que harían a veces dudoso si es o no necesaria licencia. Pero estas ocasionales incertidumbres serían las mismas que las que se dan para determinar cuándo es necesario proyecto técnico sin crear nuevos factores de inseguridad.

${ }^{45}$ Es ilustrativo A. BOIX PALOP, "La discutible necesidad de la licencia de obras menores", en J. M. BAÑO LEÓN y J. CLIMENT BARBERÁ, Nuevas perspectivas del régimen local. Estudios en homenaje al Profesor José M. ${ }^{\circ}$ Boquera Oliver, Tirant lo Blanch, Valencia, 2002, pág. 1.327 y ss., que refiriéndose a las obras menores califica su sujeción a licencia de «desproporcionado engorro» con «trámites verdaderamente superfluos». El mismo trabajo, por cierto, pone de manifiesto, la ambigüedad del concepto de obra menor (que han acogido, como hemos visto, varias leyes autonómicas para señalar lo que ahora requiere sólo comunicación o declaración responsable, ambigüedad que aconseja huir de ese término y optar, como aquí se ha hecho, por servirse del art. 2.2 LOE.

${ }_{46}$ Naturalmente que ello no supondría ninguna patente de corso para realizar obras distintas de las autorizadas. Claro está, por el contrario, que si antes de comenzar las obras o durante su realización se hacen alteraciones habrá que instar modificaciones en la licencia inicial o incluso solicitar una nueva licencia. Por supuesto, además, que si las obras realmente ejecutadas no se ajustan a las autorizadas por la licencia se estará ante uno de los supuestos que dan lugar al restablecimiento de la legalidad y, en su caso, a sanciones. Lo mismo mutatis mutandis habrá que decir respecto a las obras que superen las declaradas o comunicadas. Pero, además de que ello tiene un cierto control con el certificado que se exige para la declaración de obra nueva terminada, es un ámbito que hay que dejar a la inspección ordinaria posterior y no recargar a los administrados (ni a las mismas Administraciones) con esta carga adicional que lo complica todo extraordinaria y desproporcionadamente. 


\subsubsection{Utilización, ocupación y cambio de uso}

Destacadamente podrían -y hasta deberían- suprimirse las licencias urbanísticas de utilización, ocupación y cambio de uso. Ello en el bien entendido de que tal supresión no afectará a la permanencia de ciertos controles ambientales o de los establecidos en la legislación sectorial como la de espectáculos y actividad recreativas. Con esa salvedad, bien puede transitarse el camino que abren los arts. 11.5 y 28.1.b) LS/15 y que ya han recorrido varias Comunidades Autónomas. En concreto, se trataría de exigir sólo declaración o comunicación para la primera y sucesivas ocupaciones o utilizaciones o cambios de uso de edificaciones de nueva planta o ya existentes, casas prefabricadas e instalaciones y sea cual sea su destino (residencial, mercantil, industrial, profesional, de servicios, etc.). Es la solución más ajustada al principio de proporcionalidad pues lo que con este género de licencias se viene controlando puede ser perfectamente vigilado con declaraciones o comunicaciones unidas, desde luego, a la inspección. Por otra parte, aquí no se plantean los problemas que se generan para demoler lo construido pues es menos dramático y más fácil hacer cesar un uso ${ }^{47}$.

\subsubsection{Otros supuestos}

Junto con la reevaluación y posible supresión de licencias de obras, ocupación, utilización y cambio de uso en los términos vistos, acaso podrían también replantearse algunos otros supuestos sometidos actualmente a licencias, como por ejemplo cerramientos, trabajos previos a la construcción, pavimentación de los caminos ya existentes... Por el contrario, no parece posible suprimir la llamada declaración municipal de innecesariedad de la licencia de parcelación que, en el fondo, aunque sea chocante, ha acabado configurada como una autorización camuflada ${ }^{48}$.

\subsection{El complementario reverso de la propuesta: todas las licencias subsistentes deben tener silencio negativo}

Con esta poda de las licencias urbanísticas y su reemplazo por comunicaciones o declaraciones responsables, podría establecerse para todas las que subsistieran el silencio negativo. Así, el conjunto resultaría fácil de plasmar, sencillo de comprender y armonioso.

Aunque inicialmente se consagró la obtención de licencias urbanísticas por silencio positivo sin matizaciones $^{49}$, desde la reforma de 1975 se moderó al afirmar que no se entenderán adquiridas por silencio licencias

47 Lo afirmado respecto al inicio de obras, ocupación, utilización y cambio de uso se propone en general, no sólo para los casos cubiertos por la Ley 12/2012, para los que, como mantuvimos antes, la supresión de tales licencias es obligada por esa Ley estatal básica Ahora, con la propuesta formulada, no sería necesario referirse específicamente a ello pues las obras comprendidas en la Ley 12/2012 quedarían incluidas, junto con otras, en la regla general.

48 Por ejemplo, el art. 130.1 del Texto Refundido de la Ley de Urbanismo de Cataluña enumera los «títulos administrativos habilitantes»y, entre ellos, junto a las licencias, aparecen «las declaraciones de innecesariedad de licencia urbanística de parcelación». Y dice el art. 192 de ese Texto Refundido: «1. Toda parcelación urbanística debe ser objeto de licencia... 2. Para hacer efectivo lo que se establece en el apartado 1, debe someterse a fiscalización previa municipal toda división o segregación sucesiva de terrenos. Si la operación prevista es una parcelación urbanística, se debe autorizar o denegar... En caso contrario, el Ayuntamiento declara innecesaria la licencia de parcelación...». En Andalucía se desprende de los arts. 52.1.B in fine, $66.4,5$ y 6 y 169.1.a) de su Ley Urbanística y 8.a), 22.4.c), 28.1.II) y 28.3 del su Reglamento de Disciplina Urbanística. En teoría cabría, y sería más lógico, que cuando se tratara de divisiones de fincas que no constituyan parcelación urbanística bastara una comunicación o declaración responsable frente a la que la Administración pudiera reaccionar si observara que esconde una parcelación urbanística. Pero esa posibilidad está cerrada por la legislación estatal Estaba cerrada por al art. 11.4.a) del LS/15 que imponía la licencia expresa (con silencio negativo) para cualesquiera «parcelaciones, segregaciones y otros actos de división de fincas en cualquier clase de suelo, cuando no formen parte de un proyecto de reparcelación». Pues nótese que no se constriñe a las parcelaciones urbanísticas. Pero como ese inciso del art. 11.4.a) fue declarado inconstitucional y nulo por STC 143/2017, de 14 de diciembre, ya no es obstáculo. Donde sí hay un obstáculo es en el art. 26.2 LS/15 y en el art. 78 del RD 1093/1997. El primero exige para autorizar cualquier escritura de división de fincas y para su inscripción registral que haya algún acto que exprese la conformidad de la Administración. Y el segundo exige «el otorgamiento de la licencia que estuviese prevista por la legislación urbanística aplicable, o la declaración municipal de su innecesariedad, que deberá testimoniarse literalmente en el documento». Así las cosas, no puede ser suficiente una mera comunicación o declaración responsable del particular. Ante ello lo que quizá sería oportuno es, dejándose de eufemismos, proclamar que toda parcelación (urbanística o no) está sometida a licencia, licencia que se otorgaría entre otros casos en aquellos en los que actualmente procede esa declaración de innecesariedad.

49 Procedía conforme al art. 9.7. ${ }^{\circ}$ a) y c) RSCL de 1955, al que se remitía la LS de 1956. Vid. B. BOSCH y SALOM, La licencia municipal de obras y edificación, Ministerio de la Vivienda, Madrid, 1972, págs. 194-195. 
en contra de la legislación o del planeamiento urbanístico ${ }^{50}$. Es el silencio positivo secundum legem. En la actualidad, sin embargo, la legislación estatal impone para una serie de licencias urbanísticas el silencio negativo (art. 11.4 LS/15, parcialmente anulado), pero acepta para los demás que las leyes autonómicas mantengan el positivo secundum legem (art. 11.3 in fine) ) $^{51}$. Las legislaciones autonómicas se han acomodado a esta novedad de diversas maneras ${ }^{52}$. Según creo, lo mejor que pueden hacer las leyes autonómicas es establecer el silencio negativo sin excepciones para todas las licencias urbanísticas que pervivan una vez que se liberen ciertas actuaciones de la necesidad de obtenerlas y se sustituyan por declaración responsable. Además de que ello encaja en los cánones del art. 24.1 LPAC, muchas razones justifican esa elección, sobre todo dos. Primera, porque el silencio positivo secundum legem es, cabe decir, el compendio de todos los males sin mezcla de bien alguno: o se opta por el silencio positivo sin matizaciones (lo que quizá sería imprudente) o por el silencio negativo; pero el silencio positivo secundum legem ni es bueno para el administrado ni para la Administración ni para los intereses generales ${ }^{53}$. Segunda, porque, una vez que según la legislación estatal una serie de licencias tienen necesariamente silencio negativo, lo más sencillo es que todas tengan ese mismo silencio: cualquier otra cosa es fuente de embrollos. Así pues, silencio negativo para todas las licencias urbanísticas; ello combinado con una supresión de tales licencias y su sustitución por comunicación o declaración para ciertas actuaciones, supuesto en el que, en realidad, no hay ningún género de silencio, ni negativo ni positivo.

\subsection{Actuaciones exoneradas de toda carga formal previa}

En general, las actuaciones eximidas de licencia urbanística deben quedar sujetas a comunicación o declaración. Pero quizá convengan ciertas matizaciones o excepciones, esto es, actuaciones eximidas también de comunicación o declaración. Lo ha aceptado alguna Comunidad Autónoma ${ }^{54}$ y es adecuado al principio de proporcionalidad ante actuaciones cuya potencialidad de vulneración urbanística es nula o ínfima ${ }^{55}$. Cabría así explicitar, por ejemplo, que ciertos usos del suelo rural conforme a su destino natural no necesitan licencia ni declaración ni comunicación; o que pintar los interiores o los exteriores en la misma forma en que

50 Se incorporó al art. 178.3 del TR de LS de 1976. Después al art. 242.5 del TR de 1992, cuya constitucionalidad salvó la STC 61/1997 por entender que entraba dentro de las competencias estatales sobre bases del régimen jurídico de las Administraciones públicas y del procedimiento administrativo común. También aparecía en el TR de 2008, art. 8.b). Esto suponía algo distinto de la nulidad de la licencia ilegal conseguida por silencio: comportaba que ni siquiera se producía ese silencio positivo. Y por eso, si se ordenaba la reposición de la realidad, no había derecho a indemnización, como disponía el art. 5.2 RDU de 1978. Además, claro está, permitía denegar tardíamente la licencia sin que fuese necesaria una revisión de oficio. La complejidad inherente a este silencio positivo secundum legen aumenta si se entiende que la licencia debe ser conforme, no ya con la ordenación urbanística, sino con toda la legalidad, como sostiene M. VAQUER CABALLERÍA, “La licencia de obras", cit., págs. 79-80.

${ }^{51}$ La regla fue introducida por Real Decreto-ley 8/2011 que fue anulado por STC 29/2015 por no concurrir el presupuesto habilitante. Esta anulación, no obstante, resulta irrelevante porque lo mismo se estableció por Ley 8/2013. Ahora luce en el art. 11.3 y 4 LS/15. Aunque a su vez, como vimos, la STC 143/2017 anuló parcialmente ese art. 11.4 por superar la competencia estatal, mantiene su validez en parte y, entre otras cosas, sigue imponiendo el silencio negativo para las licencias de obras de edificación de nueva planta.

52 Radical y correcta es la solución del art. 239 del TR de la Ley de Urbanismo de Aragón y del art. 268.5 de la Ley de Ordenación Territorial y Urbanística de Murcia que optan con carácter general por el silencio negativo. Por el contrario, siguen manteniendo al menos para algunas licencias urbanísticas el silencio positivo secundum legem la Ley de Baleares (art. 151.4), la de Canarias (art. 345), la de Castilla-La Mancha (art. 161.3.2. ${ }^{\circ}$ del TR de la Ley de Ordenación Territorial y de la Actividad Urbanística), etc. Andalucía no ha modificado su Ley Urbanística (cuyo art. 172.5. ${ }^{\text {a }}$ sigue proclamando el silencio positivo) pero sí el art. 20 del Reglamento de Disciplina Urbanística que, tras reforma por Decreto 327/2012, establece para unos supuestos el silencio negativo y para otros conserva el silencio positivo secundum legem.

${ }^{53}$ Estoy, pues, de acuerdo con J. M. BAÑO LEÓN, Derecho urbanístico común, lustel, Madrid, 2009, págs. 360 y 365: «El silencio positivo secundum legem supone una contratio in terminis. El particular no puede recurrir la desestimación porque el silencio es positivo, pero tampoco tiene seguridad jurídica alguna de que los actos ejecutados en virtud de la inactividad administrativa tengan alguna validez jurídica»; “... paradójicamente, es mucho más beneficioso para el particular el silencio negativo compatible con la tutela efectiva y el resarcimiento de los daños y perjuicios producidos por la demora en el otorgamiento de la licencia (...) que el silencio (positivo) secundum legem donde el interesado queda sujeto a una situación pasiva de incertidumbre". También son muy atinadas las críticas a este silencio que formula J. C. LAGUNA DE PAZ, "La soportable levedad de las licencias urbanísticas", RDUyMA, núm. 251 (2009), págs. 24-25; más moderadamente T. QUINTANA LÓPEZ, "El silencio administrativo en el Derecho Urbanístico", en la obra colectiva coordinada por el mismo Profesor, El silencio administrativo. Urbanismo y medio ambiente, Tirant lo Blanch, Valencia, 2006, pág. 421.

${ }^{54}$ Recuérdese el antes citado art. 333 de la Ley del Suelo y Espacios Protegidos de Canarias con sus cuatro «actuaciones exentas» entre las que están «las obras de conservación y reforma consistentes en la sustitución de acabados interiores de una vivienda o local, como solados, alicatados, yesos y pinturas, cuando no estén protegidos arquitectónicamente».

55 Debe notarse que la sujeción a declaración responsable, aun siendo más suave que la necesidad de autorización, sólo cabe por razones imperiosas de interés general y sólo si es proporcionada (art. 17.2 LGUM). Es decir, lo que la Directiva de Servicios y la Ley Paraguas exigían para las autorizaciones, la LGUM lo exige para las declaraciones responsables. Vid. M. REBOLLO PUIG, "EI principio de necesidad y proporcionalidad...", cit., págs. 127 a 129. 
ya lo están tampoco queda sujeto a ninguna carga formal porque lo cierto es que algunos Ayuntamientos parten de que hasta eso requiere licencia. Naturalmente que esta exoneración dejaría incólume la necesidad de los títulos necesarios para ocupar la vía pública con andamios o contenedores, títulos que nada tienen que ver con el urbanismo ni con las licencias urbanísticas ${ }^{56}$.

\section{5. ¿Licencias voluntarias?}

Una de las críticas que se alzan frente a la sustitución de autorizaciones por comunicaciones o declaraciones es la inseguridad en que sumen al particular ${ }^{57}$. Frente a ello es conveniente que la ley no sólo prevea posibilidades de consulta al Ayuntamiento sino que, además, le dé algún valor a lo que el Ayuntamiento le informe. Como mínimo debe preverse que si el particular ha actuado de conformidad con lo que el Ayuntamiento respondió a su consulta no podrá ser sancionado.

Pero lo que ahora interesa reseñar aquí es que algunas leyes urbanísticas han ido más lejos: han establecido que el particular, pese a no necesitarla, puede pedir y obtener la licencia correspondiente ${ }^{58}$. Es una solución con sus pros pero también sus contras. De acogerse, como mínimo deben establecerse algunas prevenciones que orienten en la dirección de considerar que quien solicita estas licencias voluntarias queda sometido a todo el régimen de las licencias: prohibición de realizar la actuación hasta que se consiga la licencia, silencio negativo, etc. Sin ello la situación de este sui generis peticionario de licencia será fuente de triquiñuelas y problemas.

\section{5. ¿SUSTITUCIÓN POR COMUNICACIÓN O POR DECLARACIÓN RESPONSABLE?}

\subsection{Opción por la declaración responsable}

Vimos que algunas legislaciones autonómicas han optado por sustituir licencias urbanísticas por comunicaciones; otras por declaraciones responsables; y que incluso alguna Comunidad utiliza las dos figuras según las actuaciones de que se trate ¿Cuál es la opción preferible? La verdad es que las diferencias entre comunicaciones y declaraciones responsables son pequeñas, de escasa trascendencia y hasta discutibles ${ }^{59}$. Todo lo esencial es común. Las diferencias son secundarias y sólo están, si acaso, en lo que hay que manifestar en una y otra.

56 Aun aceptada la oportunidad de reconocer actuaciones exoneradas de toda carga formal previa no es conveniente que ello aparezca en una relación con pretensiones de exhaustividad. En principio hay que partir de que las actuaciones sometidas a licencia serán únicamente las que sujete la ley a tal autorización. Igualmente sólo necesitarán declaración responsable aquellas otras que enumere la ley con tal carga. Y todas las demás actuaciones hay que entenderlas eximidas de cualquier carga formal previa. No es, pues, necesario enunciar una serie de actuaciones no necesitadas ni de uno ni de otro requisito formal previo. Lo que sí sería oportuno es proclamar que cualquier otra actuación no comprendida entre las expresamente enunciadas como sujetas a licencia ni a declaración se puede realizar sin carga formal previa y completar esa afirmación con alguna enumeración ejemplificativa en la que se comprendan algunos de los casos exonerados de ambas cargas formales.

57 Las autorizaciones dan a su titular una cierta seguridad sobre la legalidad de su actuación que una comunicación o declaración responsable no ofrece. Cuando tiene una autorización sabe que, aunque no está al abrigo de impugnaciones o de revisiones de oficio, la Administración en principio considera legal su actividad; y hasta es posible que la anulación de su autorización le confiera derecho a indemnización. Pero cuando presenta una comunicación o declaración no sabe si a la Administración le parece legal o ilegal. Y puede que la primera noticia que tenga sobre la ilegalidad de su actividad comunicada o declarada sea la incoación de un procedimiento para sancionarle o, como mínimo, para restablecer la legalidad, con los costes que ello le irrogará. Vid. J. M. BAÑO LEÓN, "Declaración responsable y derechos de terceros. El lado oscuro de la llamada «better regulation»", en M. REBOLLO PUIG, M. LÓPEZ BENÍTEZ y E. CARBONELL PORRAS (Coords.), Régimen jurídico básico de las Administraciones Públicas. Libro homenaje al Profesor Luis Cosculluela, lustel, 2015, págs. 351 a 371; J. ESTEVE PARDO, "La deconstrucción y previsible recomposición del modelo de autorización administrativa", en A. NOGUEIRA LÓPEZ (dir. ${ }^{a}$ ), M. A. ARIAS MARTÍNEZ y M. ALMEIDA CERRADA (coords.), La termita Bolkestein. Mercado único vs. derechos ciudadanos, Civitas, 2012, págs. 38-39; M. MORA RUIZ, "Comunicación previa...", cit., pág. 271; y M. REBOLLO PUIG, "EI repliegue de las autorizaciones y la articulación de alternativas...”, cit., págs. 1.997-1.998. El mismo problema se ha presentado en Alemania como explica H. MAURER, Derecho Administrativo. Parte general, traducción española coordinada por G. DOMÉNECH PASCUAL, Marcial Pons, Madrid, 2011. En pág. 42 dice: «La exigencia de una licencia para la realización de diversos proyectos y actividades (...) no es para el interesado sólo una carga sino que también le resulta beneficiosa en cuanto con la licencia se establece de forma vinculante la legalidad del proyecto o actividad en cuestión. La actual tendencia en el marco del "adelgazamiento" de la Administración a suprimir la obligación de licencia (también) tiene la consecuencia de que se carga al ciudadano con el riesgo de la legalidad de su actividad».

58 Dice el art. 226.3 del TR de Urbanismo de Aragón (D legislativo 1/2014): «En todo caso, también puede solicitarse voluntariamente licencia para los actos de transformación, construcción, edificación o uso del suelo o el subsuelo no enumerados en el párrafo anterior cuando así lo estimen conveniente los solicitantes por razones de seguridad jurídica o de otro tipo». Asimismo, art. 263.3 de la Ley murciana 13/2015 de Ordenación Territorial y Urbanística y art. 332.2 de la Ley canaria del Suelo y Espacios Protegidos.

59 Vid. por todos F. LÓPEZ MENUDO, "La transposición de la Directiva de Servicios y la modificación de la Ley 30/1992: el régimen de la declaración responsable y de la comunicación previa”, publicado inicialmente en Revista Española de la Función Consultiva, 
Se supone que la comunicación es la nuda manifestación del particular ante la Administración de su propósito de emprender y realizar una determinada actuación. Y, frente a ello, según se desprende de los arts. 3.9 de la Ley Paraguas y 69.1 LPAC, la declaración responsable comprende, además de lo anterior: a) la manifestación de que se cumplen los requisitos establecidos en la normativa aplicable; b) que se «dispone de la documentación que así lo acredita»; c) que el declarante se compromete a seguir cumpliendo la legalidad mientras ejerza la actividad; y d) que asimismo se compromete a entregar a la Administración aquella documentación si se la requiere. Pero son diferencias puramente formales y casi insustanciales pues ni esas manifestaciones expresas son la fuente de los deberes que reconocen ni estos son ajenos a quien sólo realice una comunicación ${ }^{60}$. Para colmo, hasta esas diferencias mínimas entre declaraciones responsables y comunicaciones se han difuminado en muchas normas estatales y autonómicas ${ }^{61}$, de modo que la distinción entre declaraciones responsables y comunicaciones, además de no ser esencial, resulta borrosa y el mismo legislador bordea con titubeos la frontera entre una y otra.

Con estos datos se comprende que no es muy importante, al suprimir licencias urbanísticas, optar por comunicaciones o por declaraciones responsables. Pero como pese a todo el legislador ha distinguido entre unas y otras, la legislación urbanística debe elegir. Y puestos en ese trance más adecuada parece la declaración responsable por varias razones. Al menos por dos: porque se ajusta mejor al contenido que impone la Ley 12/2012; y porque la declaración responsable es una carga ligeramente más gravosa que la comunicación (como plasman los apartados 2 y 3 del art. 17 LGUM) que formaliza algo más solemnemente la autoevaluación y los compromisos del particular y eso resulta adecuado para este ámbito urbanístico. En cualquier caso, lo que sí debe descartarse, por ser una complicación superflua, es la solución de alguna Comunidad Autónoma (Aragón y Murcia) de prever una u otra figura según las actuaciones de las que se trate.

\subsection{Contenido}

Elegida la declaración responsable, hay que acomodar fielmente su contenido al que establece el art. 69 LPAC con solo ínfimas adaptaciones a las características de la actuación declarada. Por tanto, lo que en las declaraciones responsables urbanísticas deberá aparecer, junto con la identidad y firma de quien la hace así como fecha y órgano al que se dirige, es lo siguiente: a) identificación plena de la actividad (obras, ocupación, cambio de uso... con precisión de sus características concretas) y de su ubicación, así como del momento a partir del cual se realizará; b) manifestación de que, tras la evaluación pertinente, consta al

núm. 14 (2010), y recogido después en F. LÓPEZ MENUDO, Obra escogida, Universidad de Sevilla, Sevilla, 2018, de donde se citará. En concreto, lo que ahora interesa está en tomo I, págs. 434 a 441.

${ }_{60} \mathrm{Si}$ acaso, el compromiso de poner a disposición de la Administración la documentación exigida que debe aparecer en la declaración responsable pero no en la comunicación tiene una trascendencia mínima. Lo más importante que puede deducirse de esa precisión legal es que hay ahí una consagración implícita de la potestad administrativa de requerir del declarante la presentación de esa documentación obligatoria. Ahora bien, esa potestad y otras muchas de comprobación pueden estar previstas por las leyes para todo tipo de actividades privadas aunque no sean de las sometidas a declaración responsable, ya se trate de las que requieran mera comunicación o de las de libre acceso. Así que, frente a éstas también puede tener -y tiene frecuentemente- la Administración la potestad de requerir la documentación necesaria para ejercer la actividad. Es más, podrá ser considerada una potestad inherente a la Administración siempre que las leyes le confíen la vigilancia de cumplimiento de un sector del ordenamiento. Vid. M. REBOLLO PUIG, "La actividad inspectora", en J. J. DÍEZ SÁNCHEZ (Coord.), Función inspectora, AEPDA/INAP, 2013, pág. 62.

${ }^{61}$ Entre las estatales citemos aquí los dos ejemplos más relevantes para lo que ahora nos incumbe. De un lado, la Ley 12/2012 dice: «La declaración responsable, o la comunicación previa, deberán contener una manifestación explícita del cumplimiento de aquellos requisitos que resulten exigibles de acuerdo con la normativa vigente incluido, en su caso, estar en posesión de la documentación que así lo acredite y del proyecto cuando corresponda» (art. 4.2). Como se ve, establece exactamente el mismo contenido para la declaración responsable y para la comunicación, contenido que se corresponde con el que la legislación general da a la primera. De otro lado, el Código Técnico de la Edificación, tras su modificación por Ley 8/2013, dice: «En caso de que la exigencia de licencia o autorización previa sea sustituida por la de declaración responsable o comunicación previa, de conformidad con lo establecido en la normativa vigente, se deberá manifestar explícitamente que se está en posesión del correspondiente proyecto o memoria justificativa, según proceda» (art. 2.3 in fine). También aquí se establece un contenido para las comunicaciones que según las disposiciones generales es propio de las declaraciones responsables. Entre los ejemplos de normas autonómicas que han borrado las diferencias entre declaraciones responsables y las comunicaciones citemos los de las leyes urbanísticas antes citadas. Así, en la Ley del Suelo de Galicia, aunque se opta por las comunicaciones, se exige que en éstas haya «manifestación expresa de que (se) cumple en todos sus extremos con la ordenación urbanística de aplicación», manifestación que en principio es más propia de una declaración responsable. En igual dirección, el Texto Refundido de Urbanismo de Aragón impone como contenido de la «comunicación previa en materia de urbanismo (...) la declaración de que concurren los requisitos administrativos aplicables, especificando cuando proceda los relativos a la seguridad de personas y bienes» [art. 228.2.b)]. En normas de más amplio ámbito es ejemplo revelador la Ley 9/2013, de 19 de diciembre, de Emprendimiento y Competitividad de Galicia: sólo contempla la comunicación (art. 24), pero prevé para ella unas manifestaciones y una documentación adjunta que parecen más propias de lo que normalmente son declaraciones responsables. 
declarante que se cumplen las determinaciones de la normativa correspondiente y compromiso de que se cumplirá a lo largo de la actuación declarada62; y c) expresión de que se dispone de la documentación necesaria que lo acredita y de que se entregará a la Administración cuando se la requiera. Bueno será que la ley establezca que no cabrá exigir más datos que los señalados por ella misma o, si acaso, por reglamento autonómico de desarrollo. Así, además de garantizar un mejor cumplimiento del derecho a no dar «datos (...) no exigidos por las normas» [art. 53.1.d) LPAC], evitaría que cada municipio pueda recargar a su antojo las declaraciones responsables lo que agravaría la situación del administrado ${ }^{63}$ y crearía una diversidad contraria a la seguridad y a la posibilidad de utilizar formularios generales ${ }^{64}$.

Sobre todo debe quedar claro que no se puede aprovechar el sometimiento a declaración responsable para imponer que se manifieste el cumplimiento de requisitos que no están en las normas realmente obligatorias (por ejemplo, normas técnicas no declaradas obligatorias) o para exigir tener documentos que no son los requeridos por las normas. Menos todavía cuando ello comporte gastos adicionales. Por ejemplo, no cabe imponer por esta vía contar con certificados de organismos o entidades colaboradoras de control. Esto sólo existirá si una ley o reglamento habilitado para ello por una ley lo consagra. Esto es importante en sí y también para poner de manifiesto que la declaración responsable sólo se diferencia de la comunicación en aquello que debe contener, no en que la declaración se pueda convertir en fuente de deberes adicionales.

En lo dicho sobrevuela la cuestión de la legalidad cuyo cumplimiento hay que manifestar en estas declaraciones lo que no sólo afecta a su contenido sino a otros extremos, como los documentos adjuntos o el objeto del posterior control municipal. Esta cuestión exige un detenimiento que no puede realizarse aquí y que dejamos para otra ocasión. Ahora digamos sólo que la solución debe ser igual a la que corresponde respecto al control propio de las licencias urbanísticas y que éste debe circunscribirse al cumplimiento de la legalidad urbanística y si acaso a algún otro sector del ordenamiento si así lo ha establecido expresa e inequívocamente una norma con rango de ley.

\subsection{Documentación adjunta}

No es inusual que la legislación urbanística autonómica obligue a acompañar la comunicación o la declaración de variados documentos ${ }^{65}$. Por el contrario, el TR de Urbanismo de Aragón no exige ninguna documentación complementaria ${ }^{66}$. En principio, esta última solución es la correcta.

62 En realidad, no se trata de afirmar el cumplimiento de toda la normativa aplicable a la actuación sino sólo de una parte de ella. Abordaremos esto en "Disciplina urbanística y declaraciones...", cit., epígrafe 2.

63 Igual que ahora rechazamos que se permita a los Ayuntamientos exigir más datos que los impuestos en la ley, rechazaremos después que puedan exigir a su albur documentación complementaria. Es oportuno proclamarlo diáfanamente. Dice llanamente J. M. TRAYTER JIMÉNEZ, "Declaraciones responsables...", cit., págs. 524-525, que «la cabra tira al monte y las Administraciones públicas, desconfiadas de las nuevas técnicas de intervención y reacias a abandonar el sistema de autorización y licencia, han aprovechado los recovecos que ha dejado la normativa (...) para imponer (...) todo tipo de trabas e impedimentos (...). Normalmente, estas trabas e impedimentos se encuentran agazapados en normas reglamentarias (...). Al respecto, merece una mención especial la regulación contenida en las ordenanzas locales...». En págs. 526 a 528 se ocupa de la «exigencia en la presentación de la declaración responsable y la comunicación previa de un gran número de documentos». M. DOMÍNGUEZ MARTíN, "La transformación del control local...", cit., pág. 114 habla de la «burocratización» de las comunicaciones por la exigencia de «mucha documentación». Buen ejemplo de esos excesos ofrece A. ROSELLÓ VILA, Las licencias urbanísticas en el ámbito municipal, Tirant lo Blanch, Valencia, 2017, págs. 46 a 48 . En realidad, es una tendencia general en todos los controles previos, como explica G. DOMENECH PASCUAL, "¿Mejor antes o después? Controles públicos previos versus controles públicos posteriores", Papeles de Economía Española, núm. 151 (2017). Importa, pues, dejar claro lo que realmente se puede exigir a las comunicaciones y declaraciones y poner freno a esa tendencia malsana que puede arruinar las ventajas de la supresión de licencias.

64 No es éste un aspecto que se considere baladí. Desde la Directiva de Servicios se aspira a que todas las formalidades para la realización de actividades, además de poder realizarse a distancia por medios electrónicos, no dependan de singularidades locales que supongan una dificultad adicional para los foráneos y para la libertad de establecimiento y circulación. En esa línea por Acuerdo del Consejo de Ministros de 24 de mayo de 2013 se aprobó para la simplificación administrativa el denominado programa "Emprende en 3" para las entidades locales que se adhieran. Por Resolución de la Secretaría de Estado de Administraciones Públicas de 31 de mayo de 2013 se aprobaron las condiciones de uso, luego flexibilizadas por Resolución de la misma Secretaría de 20 de enero de 2014. Los Ayuntamientos que se adhieren se comprometen, entre otras cosas, a aceptar el modelo electrónico de declaración responsable ajustado a la Ley 12/2012 que se incluye en el Anexo y a no solicitar ninguna otra documentación «o bien la exigida por la normativa autonómica específica». Así que la adhesión cierra todo resquicio para que los Ayuntamientos (por ordenanza, plan o, menos aún, por la simple práctica) exijan datos o documentos adicionales.

65 Muestra de ello es el art. 153.1 de la Ley de Urbanismo de Baleares; el art. 349.4 de la Ley del Suelo de Canarias; el art. 105 quáter de la Ley de Urbanismo de Castilla y León; el art. 195.2.c) del Decreto Foral Legislativo; el art. 146.1 de la Ley del Suelo de Galicia; etc. Incluso en algún caso se habilita a las Ordenanzas locales para aumentar la documentación obligatoria.

${ }^{66}$ Dice su art. 227.3.c) que en la declaración responsable se debe contener «relación de los documentos acreditativos del cumplimiento de los (...) requisitos, indicando en cada caso su contenido general y el nombre del técnico o profesional que lo suscriba, sin perjuicio de que voluntariamente puedan aportarse copias de tales documentos». 
La idea que claramente subyace en el art. 3.9 de la Ley Paraguas y en el art. 69 LPAC es que la declaración responsable no necesita de ningún documento adjunto: si precisamente se impone manifestar bajo la propia responsabilidad que se cuenta con tales o cuales documentos y un compromiso de presentarlos si los requiere la Administración es porque se parte que no se presentan motu proprio con la declaración ${ }^{67}$. Pero, siendo ése el punto de partida y la regla general, puede tener excepciones. Ahora bien, la posibilidad de exigir que a las declaraciones responsables se adjunten simultáneamente documentos es limitada y debe interpretarse restrictivamente. Primero porque, como acabamos de recordar, la legislación general que conceptúa esa figura parte con claridad de la idea contraria. Segundo por el principio de simplificación administrativa. Y tercero porque en la mayoría de los casos sería contrario al art. 53.1.d) LPAC que reconoce el derecho a «no presentar (...) documentos no exigidos por las normas aplicables (...), que ya se encuentren en poder de las Administraciones Públicas o que hayan sido elaborados por éstas». Lo que deberá hacer el Ayuntamiento es proceder conforme a lo dispuesto en los apartados 2 y 3 del art. 28 LPAC. Incluso aunque no se trate de documentos ya obrantes en las Administraciones, las normas, a su vez, no pueden imponer esa carga documental a su capricho pues, al contrario, están obligadas a «evitar cargas administrativas innecesarias» (art. 129.6 LPAC). Así pues, sólo debe cargarse al declarante con la presentación de documentos adjuntos cuando se considere indispensable. $Y$ eso debe decidirlo la misma ley (si acaso, un reglamento autonómico al que se remita la ley); no los propios Ayuntamientos ni en ordenanzas ni en planes, lo que llevaría a una diversidad inoportuna y a un riego de complicar excesivamente esta carga formal ${ }^{68}$. Además, si es que se exigen documentos, deben bastar como regla general las copias (art. 28.3, 4 y 5 LPAC). Partiendo de la propuesta que antes hemos realizado sobre el ámbito de las declaraciones responsables urbanísticas podría ser una buena solución no exigir ninguna documentación complementaria o, al menos, reducirla al mínimo; acaso, por ejemplo, exigir que a la declaración responsable de primera ocupación se adjunte certificado del técnico competente sobre la conformidad de lo realizado con el proyecto autorizado por la licencia de obras ${ }^{69}$. Cuestión relevante es si hay que acompañar documentos que acrediten la obtención de autorizaciones exigidas por otra legislación. Muchas razones de fondo abonan una respuesta negativa, como explicaremos en otro lugar ${ }^{70}$. Aquí baste apuntar que eso sería difícil de conciliar con el recién recordado art. 53.1.d) LPAC.

\subsection{En especial, manifestaciones y documentos sobre cumplimiento de deberes tributarios}

El declarante o comunicante está obligado a satisfacer las tasas por la realización de las actividades de control en los supuestos, cuantía y momento en que, de acuerdo con el art. 20.4.h) e i) del Texto Refundido de la Ley de Haciendas Locales (TRHL), establezcan las correspondientes ordenanzas fiscales. E igualmente, si la actividad declarada o comunicada está sometida al impuesto sobre construcciones, instalaciones y obras (ICIO), deberá satisfacerlo en la cuantía y momento en que, de acuerdo con lo dispuesto en los arts. 100 a 103 del mismo Texto Refundido, establezca la respectiva ordenanza fiscal ${ }^{71}$. Pero lo que aquí nos interesa no son estos deberes tributarios sino en qué medida afectan al contenido y a la eficacia de las comunicaciones y declaraciones responsables. Ni la legislación estatal ni la autonómica conducen a una solución única y terminante ${ }^{72}$.

${ }^{67}$ Vid. J. I. CUBERO MARCOS, La comunicación previa, la declaración responsable y el procedimiento administrativo: especial referencia al establecimiento de actividades y a la prestación de servicios, Aranzadi, Cizur Menor, 2013, págs. 40-41.

68 Lo dicho antes sobre el programa "Emprende en 3" refuerza la imposibilidad de exigir documentos adicionales para los Ayuntamientos adheridos.

69 Así lo establece, por ej., el art. 349.4.b) de la Ley canaria 4/2017 del Suelo y los Espacios Protegidos.

70 "Disciplina urbanística y declaraciones responsables", REDA (en prensa).

71 EI TRHL (Real Decreto Legislativo 2/2004, de 5 de marzo) se modificó en dos ocasiones para tener en cuenta la sustitución de licencias municipales por declaraciones responsables o comunicaciones. Primero lo hizo la Ley de Economía Sostenible y entonces sólo se tuvo en cuenta la posibilidad de tasas por la actividad municipal de verificación del cumplimiento de los requisitos establecidos para actividades que, en sustitución de la licencia de apertura, pasaran a ser comunicadas o declaradas ante los Ayuntamientos. Después lo hizo la Ley 12/2012 que, como también eximía de ciertas licencias de obras, introdujo complementariamente la posibilidad de tasas por la verificación de las obras que desde entonces ya eran sólo objeto de comunicación o declaración responsable, así como la de ligar a éstas el ICIO. Pero para que la tasa sea exigible es necesario que se haya aprobado ordenanza fiscal acordando su imposición tras los correspondientes estudios económico-financieros. Véase la STS 1558/2016, de 28 de junio, y S. GAVIEIRO GONZÁLEZ, "Análisis de la jurisprudencia sobre las comunicaciones previas y declaraciones responsables de actividades comerciales o de servicios", RAP, núm. 205 (2018), págs. 208-209.

${ }^{72}$ La Ley 12/2012 se limitó a decir esto: «En todo caso, el declarante deberá estar en posesión del justificante de pago del tributo correspondiente cuando sea preceptivo» (art. 4.1 in fine). No ya es que no diga cuándo es preceptivo sino que no aclara si, siéndolo, ello debe ser objeto de las manifestaciones que haga el declarante o si incluso debe acompañar a su declaración o comunicación justificante 
En realidad, hay que partir de lo que cada Ayuntamiento haya establecido en sus ordenanzas fiscales sobre las formas de gestión de estos tributos: si el pago (incluso el de alguna liquidación provisional) estuviera previsto como posterior a la presentación misma de la declaración o comunicación resultaría evidente que no podría ser objeto de ésta ninguna manifestación sobre su pago. Sólo si está prevista alguna autoliquidación y pago previo es concebible que se imponga que en las declaraciones haya referencias a ello ${ }^{73}$. Pero incluso cuando los Ayuntamientos hayan instaurado alguna obligación tributaria previa a la presentación de estos documentos su incumplimiento no afecta a la eficacia de la comunicación o declaración ${ }^{74}$. Como reiteradamente dicen las leyes, la presentación de declaración o comunicación permite ya acometer la actividad, aunque no se hayan pagado las tasas y, con más razón, aunque no se haya pagado el ICIO (cuyo hecho imponible es independiente de la presentación de estos documentos) o no se hayan cumplido ciertas obligaciones formales relativas a tales tributos. Quien presente una declaración o comunicación habrá superado esa carga formal al margen de las consecuencias tributarias que ello entrañe y de que ya las haya cumplido o las cumpla después tempestivamente o las cumpla con retraso o no lo haga nunca. No afectando ni pudiendo afectar a la eficacia de las declaraciones responsables el cumplimiento de las obligaciones tributarias, parece buena solución que tampoco esto haya de ser objeto de las manifestaciones obligatorias del declarante. Lo contrario, introduciendo de soslayo estos aspectos tributarios en actos que tiene otro fin, desvirtúa su función primigenia, convierte indebidamente a estos documentos en un instrumentos para facilitar la recaudación municipal y lo complica todo. A la postre hasta es más conveniente para los intereses fiscales que los sujetos realicen cuantas declaraciones sean pertinentes sin coste económico y sin el freno que comporta y que, después, se reclamen los tributos por las vías correspondientes.

\section{MOMENTO EN QUE DEBEN PRESENTARSE LAS DECLARACIONES RESPONSABLES}

Las comunicaciones y las declaraciones admiten tres posibilidades en cuanto a su momento ${ }^{75}$.

Cabe que baste su presentación para realizar o comenzar a realizar desde ese mismo momento la actividad. Es lo que establece el art. 69.3.1. ${ }^{\circ}$ LPAC: «Las declaraciones responsables y las comunicaciones permitirán el reconocimiento o ejercicio de un derecho o bien el inicio de una actividad desde el día de su presentación...».

En segundo lugar cabe que la comunicación sea posterior al comienzo de la actividad. Lo admite el art. 69.3.2. ${ }^{\circ}$ LPAC: "... la comunicación podrá presentarse dentro de un plazo posterior al inicio de la actividad cuando la legislación correspondiente lo prevea expresamente". Por eso, ya no se habla en la LPAC, como se hacía antes, de «comunicación previa» ${ }^{76}$. Hay algunos casos en los que se ha establecido esta comunica-

de pago. En la Ordenanza tipo aprobada por la Federación Española de Municipios y Provincias el 25 de junio de 2013 se incluye como una de las declaraciones que hay que hacer; esto es, al hacer la declaración responsable correspondiente a la Ley $12 / 2012$ hay que manifestar que se cuenta con justificante de pago de los tributos correspondientes. Pero no se exige que haya que acompañar el justificante de pago. Al contrario, esa posibilidad se excluye razonadamente en sus notas. En varias de las Leyes urbanísticas autonómicas se exige expresamente que la comunicación o declaración urbanística se acompañe de justificante de pago de los tributos municipales [así, art. 146.1.e) de la Ley gallega 2/2016; y en parecidos términos, art. 158.5.c) del TR de Castilla-La Mancha]. Pero la mayoría son sibilinamente evasivas y ambiguas. Ejemplo es el Decreto andaluz 1/2016. Dice que «mediante la declaración responsable (...) la persona interesada manifestará, bajo su responsabilidad, que reúne los requisitos (...) y dispone de los documentos que se exijan, además de estar en posesión del justificante de pago del tributo correspondiente cuando sea preceptivo» (apartado 3.1). Con lo que a la postre no se sabe a ciencia cierta si, cuando es preceptivo, forma parte necesaria de las manifestaciones del declarante el decir que tiene el justificante de pago o si, aunque haya de tenerlo, eso queda al margen tales manifestaciones. Sí parece claro que no debe acompañarlo. Pese a ello, los Ayuntamientos normalmente lo exigen.

73 Incluso así, más difícil sería aceptar que se pueda obligar a adjuntar documento acreditativo de tal pago lo que parece contrario al derecho a no presentar documentos que ya obren en las Administraciones [art. 53.1d) LPAC], como será el caso de esos documentos de gestión tributaria.

74 Desde este punto de vista, declaraciones y comunicaciones son distintas de las autorizaciones porque aquéllas tienen efectos con su sola presentación sin necesitar una tramitación administrativa y aunque ni siquiera haya la más mínima actividad de verificación. Por el contrario, cuando se exige autorización la Administración puede negarse a la tramitación si no se han pagado las tasas y sin ello no habrá ninguna autorización. Por tanto, las soluciones asumidas respecto al pago de las tasas correspondientes a autorizaciones no se pueden trasladar simplistamente a las comunicaciones y declaraciones responsables.

75 Vid. J. I. CUBERO MARCOS, La comunicación previa..., cit., págs. 184 a 189.

76 Y por eso no hay que dar importancia al hecho de que algunas leyes sigan hablando de declaración responsable o comunicación «previa». Así lo hace, por sólo citar un ejemplo de los que aquí nos afectan directamente, la Ley 12/2012. Estaba en concordancia con el entonces vigente art. 71 bis de la Ley 30/1992 que sí que calificaba a las comunicaciones de previas. Pero era un adjetivo ya 
ción posterior ${ }^{77}$. Pero es difícil que la comunicación o declaración posterior cumpla adecuadamente una finalidad de control y, en cualquier caso, esa modalidad resulta inapropiada para las actuaciones urbanísticas ${ }^{78}$.

Y es posible en tercer lugar que la comunicación o declaración responsable haya de ser presentada con una cierta antelación al inicio de la actividad. A esta última modalidad no se refiere el art. 69 LPAC. Pero sigue siendo posible y lógica ${ }^{79}$. En esa dirección apunta el art. 28.1.b) LS/15 cuando, para las escrituras de obra nueva, exige como alternativa a las licencias que se acredite que se ha realizado la comunicación o declaración y que «ha transcurrido el plazo establecido para que pueda iniciarse la correspondiente actividad». Así, durante el plazo de preaviso la Administración tendrá tiempo de tomar medidas, incluso prohibitivas, antes de que se comience la actividad evitando expeditivamente y de raíz, por tanto, toda actuación ilegal ${ }^{80}$.

En el modesto ámbito en el que las declaraciones responsables urbanística son procedentes conforme a la Ley estatal 12/2012 no se ha establecido ese preaviso: las actividades declaradas se pueden realizar en el mismo día de su presentación. Por el contrario, como vimos antes, en la legislación urbanística de algunas Comunidades Autónomas (Baleares, Canarias, Cataluña, Extremadura y Galicia) sí se ha establecido su antelación con plazos de entre un día y un mes.

Aunque lo permite el inciso recién transcrito del art. 28.1.b) LS/15, no es oportuno seguir este modelo del preaviso que lo complica todo. Por una parte, porque como la Ley 12/2012 permite realizar la actividad el mismo día de la presentación, para respetarla habría que distinguir entre las actuaciones que están en el ámbito de esa Ley (para las que no habría antelación) y las restantes. Por otra parte, supondría que acreditar la simple presentación de la comunicación o declaración responsable no sería suficiente para realizar escrituras públicas de obra nueva ni para su acceso al Registro de la Propiedad sino que sería necesario algún otro documento complementario con la complicación a ello inherente ${ }^{81}$. E iguales engorros surgirían para contratar los suministros de electricidad, agua, gas o telecomunicaciones ${ }^{82}$.

Pero si pese a todo eso se opta por imponer cierta antelación, al menos debe quedar meridianamente claro que la potestad municipal de reaccionar frente a las ilegalidades de la declaración o comunicación no queda constreñida a esos plazos de preaviso tan fugaces ${ }^{83}$. En cualquier caso, lo que sí es seguro es que

entonces insustancial. Incluso la Ley 12/2012, habla, incurriendo en incongruencia con esa calificación de previa, del oxímoron de «la comunicación previa dentro de un plazo posterior al inicio o desarrollo de las actividades comerciales y de prestación de servicios».

77 Por ejemplo, para realizar la actividad de franquiciador o de venta a distancia se ha impuesto una comunicación en un plazo de tres meses desde el inicio de tal actividad; arts. 38.2 y 62.2 de la Ley de Ordenación del Comercio Minorista en la redacción dada por Ley $1 / 2010$.

78 Cosa por completo distinta es que la declaración responsable o la comunicación tardía tenga eficacia desde el mismo momento de su presentación. Eso puede y debe aceptarse. Pero no impide afirmar que esa presentación posterior al inicio de la actividad suponga la ilicitud de lo realizado antes: fue ilegal la realización de la actividad desde que comenzó hasta que se presentó la comunicación o declaración y se habrá incurrido durante ese periodo en una infracción merecedora de sanción.

79 Y, de hecho, prevista en muchas normas. Vid. F. LÓPEZ MENUDO, “La transposición....", cit., págs. 447-448.

80 Ante ello se habla a veces de comunicaciones con posibilidad de veto. Vid. M. C. NúÑEZ LOZANO, Las actividades comunicadas..., cit., págs. 26, 77, 113-114, 120, 128 y ss., y 163 a 171. F. LÓPEZ MENUDO, “La transposición...”, cit., págs. 447-448 las Ilama comunicaciones «con eficacia demorada».

81 Fácil es para el notario comprobar que se ha presentado la declaración responsable y que ha transcurrido el plazo de preaviso. Lo difícil será comprobar que durante ese plazo el Ayuntamiento no ha puesto objeción. El medio más lógico sería un certificado municipal que acreditara que se ha superado el plazo de preaviso sin que se haya tomado ninguna medida en contra. Pero ello comportaría retrasos y complicaciones. En cierto modo, produciría también una desnaturalización de la declaración responsable y su conversión, o casi, en una autorización. Téngase en cuenta que tanto la Directiva de Servicios (art. 4.6) como la Ley Paraguas (art. 3.6) y la LGUM [Anexo, apartado f)] consideran que hay autorización siempre que se exija un acto expreso o tácito (u "obtener un documentos oficial», dice la Directiva) para realizar una actividad. Aquí, si se exigiese un certificado administrativo, no se trataría exactamente de eso pero sí de algo parecido que arruinaría la simplificación propia de la sustitución de la licencia por una declaración.

82 La legislación autonómica ha convertido las licencias en requisito para la contratación de los suministros de agua, electricidad, gas o telecomunicaciones. Al sustituirse tales licencias por comunicaciones o declaraciones responsables basta acreditar ante las compañías suministradoras la presentación de éstas. Así lo han previstos varias Comunidades Autónomas: art. 336 de la Ley canaria 4/2017 del Suelo y de los Espacios Protegidos; art. 164.2.d) del TR castellano-manchego de Ordenación del Territorio y de la Actividad Urbanística; apartado 6 del artículo único del Decreto andaluz 1/2016, con la singularidad problemática de que lo circunscribe al suelo urbano consolidado y de que no se ha modificado el art. 175 LOUA; etc. Pero si se establece un plazo de preaviso parece que sería necesario acreditar antes las compañías no sólo que se presentó con esa antelación sino que durante ese tiempo el Ayuntamiento no ha reaccionado con lo que surgirían los mismos problemas expuestos para realizar escrituras públicas.

83 Así F. LÓPEZ MENUDO, “La transposición...”, cit., pág. 449: «... no vemos base jurídica alguna que permita sostener que el transcurso del plazo (de preaviso) conlleve la caducidad de la potestad de control» que «podrá ejercerse en cualquier momento, exista o no un periodo específico para vetar la actividad...». También lo acepta J. M. BAÑO LEÓN, "Declaración responsable...", cit., pág. 355: “... el transcurso del plazo (de preaviso) habilita a desarrollar la actividad, pero no implica reconocimiento de derecho subjetivo, pudiendo prohibirse o modificarse los términos en que la actividad se ejerce en cualquier tiempo si la Administración si la Administración demuestra que la actividad no se ajusta a Derecho". Cosa distinta es que lege ferenda postule la solución opuesta por la asimilación de 
la decisión de establecer plazos de preaviso debe tomarla el mismo legislador y no permitir que sean los Ayuntamientos, a través de planes u ordenanzas, los que impongan la presentación de las declaraciones con antelación.

Ya se opte por admitir las declaraciones el mismo día de comienzo de la actividad o por imponer una cierta antelación, la declaración podrá voluntariamente presentarse antes de ese momento. Pero ello puede tener límites. Y seguramente es oportuno que los tenga y que la ley los establezca. Igual que las licencias urbanísticas caducan si no se emprende la actividad autorizada en cierto tiempo, es razonable que las declaraciones responsables, al menos las relativas a obras, tengan también un plazo de eficacia y que caduquen si la actividad no se acomete y termina en cierto tiempo, como permite el último párrafo del art. 7.1 de la Ley Paraguas ${ }^{84}$.

La determinación del momento de presentación de las declaraciones responsables urbanísticas se relaciona también con la cuestión de si tienen que ser posteriores a la obtención de autorizaciones o a la realización de comunicaciones o declaraciones impuestas por otra legislación sectorial. Aunque esto requiere un tratamiento específico que abordaremos en otra ocasión ${ }^{85}$, digamos aquí al menos que la solución preferible y la que conviene establecer como regla general es la de no imponer un concreto orden entre los diversos controles administrativos y, en consecuencia, permitir que la comunicación o declaración responsable urbanística se presente antes, después o simultáneamente a la presentación de otras comunicaciones o declaraciones o a la obtención -y hasta la solicitud- de eventuales autorizaciones concurrentes.

\section{BIBLIOGRAFÍA}

BAÑO LEÓN, J. M. (2009): Derecho urbanístico común. Madrid: lustel.

BAÑO LEÓN, J. M. (2015): "Declaración responsable y derechos de terceros. El lado oscuro de la llamada «better regulation»", en REBOLLO PUIG, M., LÓPEZ BENITTEZ, M. y CARBONELL PORRAS, E. (coords.): Régimen jurídico básico de las Administraciones Públicas. Libro homenaje al Profesor Luis Cosculluela. Madrid: lustel.

BOIX PALOP, A. (2002): "La discutible necesidad de la licencia de obras menores", en BAÑO LEÓN, J. M. y CLIMENT BARBERÁ, J. (coords.): Nuevas perspectivas del régimen local. Estudios en homenaje al Profesor José M. ${ }^{\circ}$ Boquera Oliver. Valencia: Tirant lo Blanch.

BOSCH Y SALOM, B. (1972): La licencia municipal de obras y edificación. Madrid: Ministerio de la Vivienda.

DOMÍNGUEZ MARTÍN, M. (2017): "La transformación del control local: de la licencia urbanística a la actuación comunicada", en Revista de Derecho Urbanístico y Medio Ambiente, núm. 311.

CHINCHILLA PEINADO, J. A. (2008): "El control municipal de los actos de uso del suelo y edificación a través de la figura de la comunicación previa como alternativa a la licencia urbanística: análisis de la regulación legal y municipal y de la aplicación judicial", en Revista de Derecho Urbanístico y Medio Ambiente, núm. 42.

CUBERO MARCOS, J. I. (2013): La comunicación previa, la declaración responsable y el procedimiento administrativo: especial referencia al establecimiento de actividades y a la prestación de servicios. Cizur Menor: Aranzadi.

DOMENECH PASCUAL, G. (2017): “¿Mejor antes o después? Controles públicos previos versus controles públicos posteriores", en Papeles de Economía Española, núm. 151.

ESTEVE PARDO, J. (2012): "La deconstrucción y previsible recomposición del modelo de autorización administrativa", en NOGUEIRA LÓPEZ, A. (dir. $\left.{ }^{a}\right)$, ARIAS MARTÍNEZ, M. A. y ALMEIDA CERRADA, M. (coords.): La termita Bolkestein. Mercado único vs. derechos ciudadanos. Cizur Menor: Civitas.

GAVIEIRO GONZÁLEZ, S. (2018), "Análisis de la jurisprudencia sobre las comunicaciones previas y declaraciones responsables de actividades comerciales o de servicios", Revista de Administración Pública, núm. 205.

la superación de ese plazo con la obtención de un acto presunto favorable por silencio, propuesta que desborda lo que ahora nos ocupa ( vid. "Disciplina urbanística y declaraciones responsables", cit., epígrafe 4) y de la que suficiente será aquí decir que discrepo respetuosa pero rotundamente. Además de falta de base legal y dogmática y muy perjudicial para los intereses generales, la identificación de los plazos de preaviso con un término fatal a partir del cual ya no podría reaccionar la Administración contra la actividad comunicada sería letal para los intereses de terceros (por ejemplo, vecinos) que verían que, tras una comunicación de la que ni siquiera han tenido conocimiento, se consolida una situación ilegal y lesiva para sus intereses.

${ }^{84}$ Es expresión de ello el art. 105 quáter de la Ley de Urbanismo de castellanoleonesa: «Los actos legitimados por declaración responsable deberán ejecutarse dentro de los plazos de inicio, interrupción máxima y finalización que se determinen reglamentariamente (...) El régimen de caducidad será el señalado en el art. 103», o sea, el establecido para las licencias. Y el art. 314 quáter.5 de su Reglamento establece: «Los actos de uso del suelo amparados por declaración responsable deben realizarse dentro de los siguientes plazos de inicio y finalización, sin posibilidad de interrupción ni de prórroga, cumplidos los cuales la declaración se entiende caducada: a) Plazo de inicio: antes de un mes desde la presentación de la declaración. b) Plazo de finalización: antes de seis meses desde la presentación de la declaración».

85 "Disciplina urbanística y declaraciones responsables", epígrafe 3. 
GONZÁLEZ BUSTOS, M. A. (2016): "Simplificación administrativa, licencias urbanísticas y declaración responsable”, en Revista Jurídica de Castilla y León, núm. 39.

IGLESIAS GONZÁLEZ, F. (2000): Licencias urbanísticas. Madrid: Francis Lefebvre.

LAGUNA DE PAZ, J. C. (2009): "La soportable levedad de las licencias urbanísticas", en Revista de Derecho Urbanístico y Medio Ambiente, núm. 251.

LÓPEZ MENUDO, F. (2010): "La transposición de la Directiva de Servicios y la modificación de la Ley 30/1992: el régimen de la declaración responsable y de la comunicación previa", publicado inicialmente en Revista Española de la Función Consultiva, núm. 14, y recogido después en LÓPEZ MENUDO, F., Obra escogida, Editorial Universidad de Sevilla, Sevilla, 2018.

LOZANO CUTANDA, B. (2013): "Ley 12/2012, de medidas urgentes de liberalización del comercio minorista y determinados servicios", en Revista CESCO de Derecho del Consumo, núm. 5.

MAURER, H. (2011): Derecho Administrativo. Parte general, traducción española coordinada por DOMÉNECH PASCUAL, G. Madrid: Marcial Pons.

MORA RUIZ, M. (2012): "Comunicación previa, declaración responsable y control posterior de la actividad en el ámbito local: aproximación a su régimen jurídico ¿Nuevas técnicas administrativas?”, en Revista Española de Derecho Administrativo, núm. 155.

NIETO-GUERRERO LOZANO, A. M. (2007): Licencia urbanística y comunicación previa de obras. Cizur Menor: Aranzadi.

NÚÑEZ LOZANO, M. C. (2001): Las actividades comunicadas a la Administración. La potestad administrativa de veto sujeta a plazo. Madrid: Marcial Pons.

NÚÑEZ LOZANO, M. C. (2011): "Aproximación del régimen jurídico de las declaraciones responsables y comunicaciones", en Noticias de la Unión Europea, núm. 317.

NÚÑEZ LOZANO, M. C. (2013): "La transposición de la Directiva de Servicios en la ordenación del comercio. En especial, la previsión de autorizaciones, declaraciones responsables y comunicaciones”, en REBOLLO PUIG , M. (dir.): Derecho de la regulación económica, IX, Comercio interior. Madrid: Iustel.

NÚÑEZ LOZANO, M. C. (2015): "Las declaraciones responsables y las comunicaciones en el Proyecto de Ley del Procedimiento Administrativo Común de las Administraciones Públicas", en Documentación Administrativa, nueva época, núm. 2. DOI: https://doi.org/10.24965/da.v0i2.10272.

QUINTANA LÓPEZ, T. (2006): “EI silencio administrativo en el Derecho Urbanístico”, en QUINTANA LÓPEZ, T. (coord.): El silencio administrativo. Urbanismo y medio ambiente. Valencia: Tirant lo Blanch.

REBOLLO PUIG, M. (2013): "La actividad inspectora", en DÍEZ SÁNCHEZ, J. J. (coord.): Función inspectora. Madrid: AEPDA/INAP.

REBOLLO PUIG, M. (2014): "El repliegue de las autorizaciones y la articulación de alternativas. En especial, la tutela de los terceros perjudicados por actividades privadas ilegales", en SORIANO GARCÍA, J. E. (dir.) y ESTEPA MONTERO, M. (coord.): Por el Derecho y la libertad. Libro homenaje al Profesor Juan Alfonso Santamaría Pastor. Madrid: lustel.

REBOLLO PUIG, M. (2017): "El principio de necesidad y proporcionalidad de los límites a las actividades económicas", en GUILLÉN CARAMÉS, J. y CUERDO MIR, M. (dirs.) y RAMS RAMOS, L. (coord.): Estudios sobre la Ley de Garantía de la Unidad de Mercado. Cizur Menor: Civitas.

REBOLLO PUIG, M. (2015): "El Estado autonómico tras la Ley de Garantía de la Unidad de Mercado y sus principios de necesidad y eficacia nacional”, en Revista Andaluza de Administración Pública, núm. 91, y en LÓPEZ BENÍTEZ, M., FUENTETAJA PASTOR, J. A., y RODRÍGUEZ-CAMPOS GONZÁLEZ, S., Las reformas administrativas de la crisis. Civitas, 2017.

RIVERO ORTEGA, R. (2009): "La trasposición de la Directiva de Servicios en España”, en RIVERO ORTEGA, R. (dir.): Mercado europeo y reformas administrativas. La transposición de la Directiva de Servicios en España. Cizur Menor: Civitas.

ROSELLÓ VILA, A. (2017): Las licencias urbanísticas en el ámbito municipal. Valencia: Tirant lo Blanch.

TRAYTER JIMÉNEZ, J. M. (2015): “Declaraciones responsables, comunicaciones previas y derechos de los ciudadanos", en REBOLLO PUIG, M., LÓPEZ BENÍTEZ, M., y CARBONELL PORRAS, E. (coords.): Régimen jurídico básico de las Administraciones Públicas. Libro Homenaje al Profesor Luis Cosculluela. Madrid: lustel.

VAQUER CABALLERÍA, M. (2013): "La licencia de obras", en PAREJO ALFONSO, L. (dir.): Autorizaciones y licencias, hoy. Valencia: Tirant lo Blanch. 